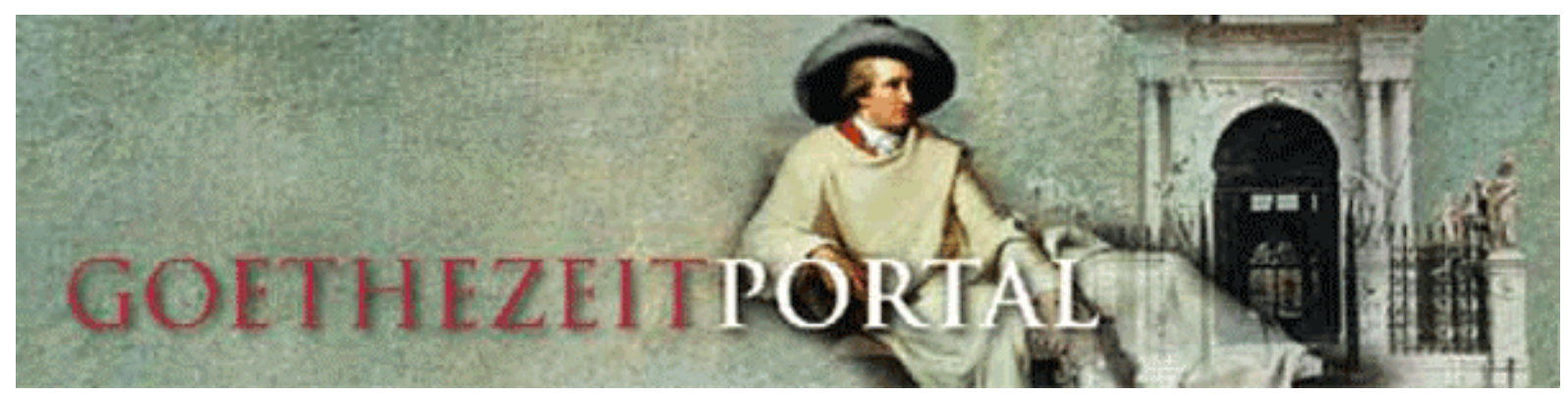

CHRISTIAN BEGEMANN

\title{
Brentano und Kleist vor Friedrichs Mönch am Meer. Aspekte eines Umbruchs in der Geschichte der Wahrnehmung ${ }^{1}$
}

\author{
Vorblatt
}

\section{Publikation}

Erstpublikation: Deutsche Vierteljahrsschrift für Literaturwissenschaft und Geistesgeschichte 64 (1990), S. 89-145.

Neupublikation im Goethezeitportal

Vorlage: Datei des Autors

URL: <http://www.goethezeitportal.de/db/wiss/epoche/begemann_wahrnehmung.pdf>

Eingestellt am 17.02.2006

\section{Autor}

Prof. Dr. Christian Begemann

Universität Bayreuth

Neuere deutsche Literaturwissenschaft

95440 Bayreuth

E-mail-Adresse: <Christian.Begemann@uni-bayreuth.de>

Homepage: <http://www.uni-bayreuth.de/departments/ndl/begemann.htm>

\section{Empfohlene Zitierweise}

Beim Zitieren empfehlen wir hinter den Titel das Datum der Einstellung oder des letzten Updates und nach der URL-Angabe das Datum Ihres letzten Besuchs dieser Online-Adresse anzugeben: Christian Begemann: Brentano und Kleist vor Friedrichs Mönch am Meer. Aspekte eines Umbruchs in der Geschichte der Wahrnehmung (17.02.2006). In: Goethezeitportal. URL: <http://www.goethezeitportal.de/db/wiss/epoche/begemann_wahrnehmung.pdf> (Datum Ihres letzten Besuches). 


\author{
Brentano und Kleist vor \\ Friedrichs Mönch am Meer \\ Aspekte eines Umbruchs in der Geschichte der Wahrnehmung ${ }^{1}$ \\ Von Christian Begemann (Bayreuth)
}

\begin{abstract}
In den "Empfindungen vor Friedrichs Seelandschaft" von Brentano und Kleist läßt sich ein wahrnehmungsgeschichtlich signifikanter Bruch nachweisen. Geht Brentano von der romantischen Konzeption der Sehnsucht aus, so stehen hinter dem Text Kleists die Theorie des Erhabenen und die Assoziation des Panoramas. Diese konkurrierenden Positionen gründen in unterschiedlichen Begriffen vom Subjekt.

In the "Empfindungen vor Friedrichs Seelandschaft" by Brentano and Kleist we can trace a break which is relevant in terms of the history of perception. While Brentano bases his argument on the Romantic concept of longing ("Sehnsucht"), Kleist's text is influenced by the theory of the sublime and the association of the panorama. These competing positions arise from different concepts of the subject.
\end{abstract}

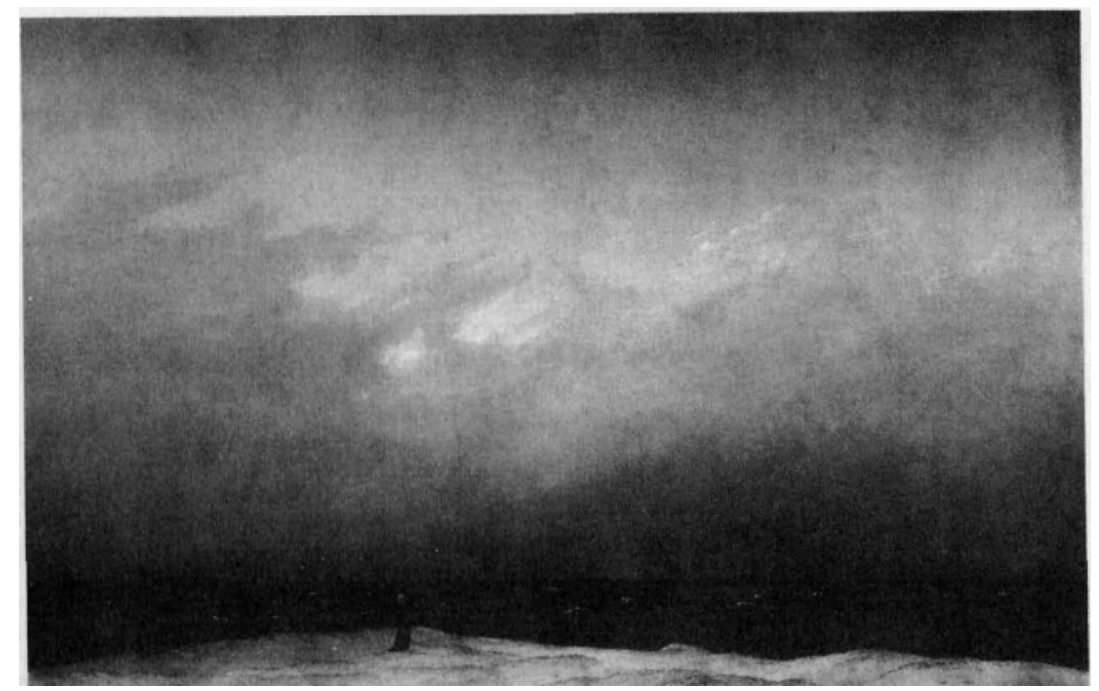

Abb. l: Caspar David Friedrich, Der Mönch am Meer

Als Caspar David Friedrichs Gemälde Der Mönch am Meer (Abb. 1) im Herbst des Jahres 1810 auf der Berliner Akademieausstellung gezeigt wurde, scheint das gebildete Publikum zwiespältig reagiert zu haben. Trotz allerhöchster Anerkennung - der preußische Kronprinz, der spätere König Friedrich Wilhelm IV., erwarb das Bild zusammen mit der gleichzeitig ausgestellten Abtei im Eichwald - und trotz der angeblichen Bereitschaft aller "unbefangenen Kunstfreunde und Kenner," dem Maler "volle Gerechtigkeit wiederfahren" zu lassen, ${ }^{2}$ überwiegen doch Zeugnisse, aus denen Befremden und Irritation spricht. ${ }^{3}$ Das bedeutendste Dokument der Rezeption ist eine kurze, mit "cb." gezeichnete Besprechung, die am 13. Oktober 1810 in den von Heinrich von Kleist herausgegebenen Berliner Abendblättern erschien: 


\section{EMPFINDUNGEN VOR FRIEDRICHS SEELANDSCHAFT}

Herrlich ist es, in einer unendlichen Einsamkeit am Meeresufer, unter trübem Himmel, auf eine unbegränzte Wasserwüste, hinauszuschauen. Dazu gehört gleichwohl, daß man dahin gegangen sei, daß man zurück muß, daß man hinüber mögte, daß man es nicht kann, daß mam Alles zum Leben vermißt, und die Stimme des Lebens dennoch im Rauschen der Fluth, im Wehen der Luft, im Ziehen der Wolken, dem einsamen Geschrei der Vögel, vernimmt. Dazu gehört ein Anspruch, den das Herz macht, und ein Abbruch, um mich so auszudrücken, den Einem die Natur thut. Dies aber ist vor dem Bilde unmöglich, und das, was ich in dem Bilde selbst finden sollte, fand ich erst zwischen mir und dem Bilde, nehmlich einen Anspruch, den mein Herz an das Bild machte, und einen Abbruch, den mir das Bild that; und so ward ich selbst der Kapuziner, das Bild ward die Düne, das aber, wo hinaus ich mit Sehnsucht blicken sollte, die See, fehlte ganz. Nichts kann trauriger und unbehaglicher sein, als diese Stellung in der Welt: der einzige Lebensfunke im weiten Reiche des Todes, der einsame Mittelpunct im einsamen Kreis. Das Bild liegt, mit seinen zwei oder drei geheimnißvollen Gegenständen, wie die Apokalypse da, als ob es Joungs Nachtgedanken hätte, und da es, in seiner Einförmigkeit und Uferlosigkeit, nichts, als den Rahm, zum Vordergrund hat, so ist es, wenn man es betrachtet, als ob Einem die Augenlieder weggeschnitten wären. Gleichwohl hat der Mahler Zweifels ohne eine ganz neue Bahn im Felde seiner Kunst gebrochen; und ich bin überzeugt, daß sich, mit seinem Geiste, eine Quadratmeile märkischen Sandes darstellen ließe, mit einem Berberitzenstrauch, worauf sich eine Krähe einsam plustert, und daß dies Bild eine wahrhaft Ossiansche oder Kosegartensche Wirkung thun müßte. Ja, wenn man diese Landschaft mit ihrer eignen Kreide und mit ihrem eigenen Wasser mahlte; so, glaube ich, man könnte die Füchse und Wölfe damit zum Heulen bringen: das Stärkste, was man, ohne allen Zweifel, zum Lobe für diese Art von Landschaftsmahlerei beibringen kann. - Doch meine eigenen Empfindungen, über dies wunderbare Gemählde, sind zu verworren; daher habe ich mir, ehe ich sie ganz auszusprechen wage, vorgenommen, mich durch die Aeußerungen derer, die paarweise, von Morgen bis Abend, daran vorübergehen, zu belehren.

cb. ${ }^{4}$

Dieser unzugängliche, in vielem rätselhafte Text ist von erheblicher Signifikanz für eine Geschichte der Wahrnehmung. Friedrichs Gemälde nämlich hat seine Betrachter offenbar dazu herausgefordert, die Stellung des Subjekts in der Weite des Raums sowie deren künstlerische Darstellung zu reflektieren - ein Thema, das im Gefolge der frühneuzeitlichen kosmologischen Revolutionen bekanntlich größte Bedeutung für die Malerei, Literatur und Ästhetik des 18. Jahrhunderts gewonnen hatte. Um 1800 scheint hier ein Umbruch stattgefunden zu haben. Er hat sich der Besprechung der Abendblätter eingeschrieben.

Auf die literatur- und kunstgeschichtliche Forschung hat dieser Text eine beträchtliche Faszination ausgeübt, meist allerdings eine, die in kuriosem Mißverhältnis zum Verständnis dessen stand, was in ihm gesagt wird. Wohl selten ist ein Text mit solcher Willkürlichkeit und philologischer Nonchalance zitiert worden wie dieser, und das hatte unausbleibliche interpretatorische Konsequenzen. Dabei sind die philologischen Fakten längst bekannt. ${ }^{5}$ Der Veröffentlichung in den Abendblättern liegt ein etwa sechsseitiger Text zugrunde, den Clemens Brentano unter Mitarbeit Achim von Arnims verfaßt hatte. Auf eine kurze reflektierende Einleitung folgt hier eine lockere Reihe ironisch gezeichneter Gespräche unter Besuchern der Ausstellung. ${ }^{6}$ Nach Kleists rigoroser Redaktion bleiben davon freilich nur die einführenden Sätze übrig, und auch diese nicht ganz unverändert. Die zweite Hälfte der Besprechung (ab "Nichts kann trauriger und unbehaglicher sein [...]") stammt im wesentlichen von Kleist - im wesentlichen, denn immer wieder bedient dieser sich bei Brentano, bricht aus dessen Vorgabe einzelne Teile heraus, um sie einem veränderten Kontext einzufügen. Brentanos Ärger über dieses Verfahren war so groß, daß Kleist sich nicht nur zu Entschuldigungen, ${ }^{7}$ sondern am 22. Oktober auch zu einer öffentlichen "Erklärung" veranlaßt sah, in der er den Sachverhalt darlegte und die "Verantwortlichkeit" für den Aufsatz übernahm. ${ }^{8}$ 
Auf derlei scheinbare Quisquilien hat sich die Forschung in der Regel ebensowenig eingelassen wie auf eine ernsthafte Untersuchung dessen, was im Text eigentlich steht. ${ }^{9}$ Kommentarlos, als gäbe es nichts Selbstverständlicheres als ihn, begnügt man sich meist mit dem dekorativen Zitieren einzelner Highlights, an erster Stelle des Bildes von den weggeschnittenen Augenlidern, und kompensiert die interpretatorische Abstinenz durch Apodiktik. Entsprechend beliebig bleibt dabei, ob man sich dafür entscheidet, die Besprechung sei kongenial oder doch eher ein Verriß. ${ }^{10}$ Für ein eingehenderes Verständnis des Texts dürften freilich beim landläufigen Ignorieren der philologischen Gegebenheiten die Chancen auch schlecht stehen. Wo man nicht den Text für einen einheitlichen gehalten und Kleist als seinen alleinigen Urheber angesehen, ${ }^{11}$ sondern immerhin die Umarbeitungssituation überhaupt zur Kenntnis genommen hat, hat sich ein weites Feld der Verwechslungen geöffnet: Kleist-Sätze werden Brentano zugeschrieben, ${ }^{12}$ Formulierungen aus der Feder Brentanos gelten als solche Kleists; ${ }^{13}$ selbst für Brentanos "Ausstellungsgespräch" muß Kleist verschiedentlich als Autor oder Mitautor firmieren. ${ }^{14}$

Solche Mißgriffe würden lediglich das Peinlichkeitsgefühl berühren, wären sie nicht Griffe in die Augen des Interpreten. Sie vereiteln die Wahrnehmung eines entscheidenden Sachverhalts, den Kleist selbst in seiner "Erklärung" angedeutet hat:

Gleichwohl hat dieser Aufsatz dadurch, daß er nunmehr ein bestimmtes Unheil ausspricht, seinen Charakter dergestalt verändert, daß ich, zur Steuer der Wahrheit... erklären muß: nur der Buchstabe desselben gehört den genannten beiden Hrn. [Brentano und Arnim]; der Geist aber, und die Verantwortlichkeit dafür, so wie er jetzt abgefaßt ist, mir. ${ }^{15}$

Mit diesem Satz weist Kleist auf eine Differenz zwischen seiner Position und derjenigen Brentanos (und Arnims) hin, behauptet aber zugleich, diese Differenz in einem einheitlichen "Geist" aufgehoben, d.h. die übernommenen Textstücke seiner eigenen Konzeption integriert zu haben. Letzteres allerdings erscheint einigermaßen problematisch. Wer genau hinsieht, bemerkt nicht allein, daß Kleist die Stelle, an der er Brentanos Text schneidet und mit eigenen Worten fortfährt, nur dürftig verfugt, sondern auch, daß ein Dissens keineswegs nur in Kleists Ablehnung von Brentanos 'unbestimmter' Auseinandersetzung mit dem Gemälde im Geist romantischer Ironie liegt. Ein Dissens nämlich ist auch im redigierten Text der Abendblätter noch deutlich sichtbar: Beide Autoren argumentieren offenkundig aus ganz verschiedenen, letztlich unvereinbaren Positionen. ${ }^{16}$ Versuche einer homogenisierenden Interpretation, die sich auf Kleists Diktum vom einheitlichen "Geist" des Texts berufen könnten, müssen, so scheint mir, an diesem Sachverhalt ebenso scheitern wie Kleist an der Widerständigkeit der Sätze Brentanos.

Ich möchte daher im folgenden den Riß im Text, die Differenz zwischen den Argumentationsbasen beider Autoren freilegen. Dazu soll eine am Text entlanggehende mikrologische Lektüre mit der Analyse der jeweiligen historischen Hintergründe und Bezugspunkte kombiniert werden. ${ }^{17}$

I.

Die ersten, von Brentano stammenden Sätze der Besprechung bleiben ganz im Vorfeld einer Auseinandersetzung mit dem Gemälde, legen zugleich aber den Grund für diese. Nicht von "Empfindungen vor Friedrichs Seelandschaft" ist die Rede, sondern von Empfindungen vor einer wirklichen Seelandschaft. Das Bild wird also zunächst nicht als Kunstprodukt genommen, sondern als Anlaß, die reale Situation seines Gegenstands zu analysieren, die Situation eines einsamen Betrachters einer "unbegränzte[n] Wasserwüste." Ein solcher Ausblick, so heißt es, ist "herrlich," allerdings auf eine besondere, gebrochene, geradezu paradoxe Weise. 
Ein heftiges Ungenügen, ein Mangelzustand, in dem "man Alles zum Leben vermißt," bildet die dunkle Folie der Faszinationskraft des Meeres. Freiwillig sucht man dessen Ufer auf, denn hier bietet sich eine Verheißung, eine Verheißung, die eine visuelle und eine akustische Komponente hat. Zum einen läßt die Unbegrenztheit der Aussicht den Blick ungehindert in die Ferne gleiten, die lockend erscheint, "mögte" man doch "hinüber." Zum anderen vernimmt man "im Rauschen der Fluth, im Wehen der Luft, im Ziehen der Wolken, dem einsamen Geschrei der Vögel" die "Stimme des Lebens": ${ }^{18}$ Eine Ahnung berührt das einsame Subjekt, ein Vor-Schein, oder besser: ein Vor-Klang all dessen, was es in seiner alltäglichen Welt "vermißt." Der Begriff des Lebens lädt sich emphatisch auf, bleibt dabei aber schwer zu fassen. Er ist primär Negation des schlechten Gegebenen und bildet als solche den Inbegriff des Vermißten. Positiv gefüllt wird er durch Attribute, die in den gewählten Bildern liegen. Neben Klang bzw. Geräusch ist vor allem das Moment der Bewegung wesentlich, das den Ruf des Lebens mit dem Bild der Ferne verbindet, da die ziehenden Wolken und fliegenden Vögel auch zur Sogwirkung des Horizonts auf den Blick beitragen dürften. Die Bilder der unbegrenzten Flut und der Luft, die in diesem Zusammenhang an ältere Äther-Konzepte erinnert, verweisen auf einen weiteren Aspekt: In ihnen wird "Leben" als ein strömendes, wogendes, allumfassendes Totum gedacht. Das Gegebene und Normale, das vom "Leben" abgeschnitten ist, zeigt sich indirekt als ein klar Umrissenes, Begrenztes, Verfestigtes und Erstarrtes, das in seiner drükkenden Enge den Wunsch nach Befreiung und endloser Bewegung, Entgrenzung und Aufgehen in einem flutenden Ganzen weckt. Diese sirenenhafte Lockung des Lebens ist neben der Verheißung der Ferne gemeint, wenn im folgenden Satz von einem "Anspruch, den das Herz macht," die Rede ist. Von dem zuletzt genannten Aspekt her bleibt nun allerdings zu präzisieren, daß man sich die Bewegung des Blicks in die Ferne nicht zu 'zielstrebig,' deren utopischen Gehalt nicht zu plastisch vorstellen sollte. Im Zusammenhang mit dem Lebensbegriff ist es wenig wahrscheinlich, daß jenseits der Grenze des Sichtbaren, der Horizontlinie, ein konkreter Raum der Erfüllung, ein Elysium oder Tahiti, lokalisiert würde, in den "man hinüber mögte." Die Vorstellung des Drüben bleibt vielmehr so diffus wie die Formulierung leer von Konkretionen. Und mit der Wahl des Wortes "hinüber" scheint der Schwerpunkt des Wunsches ohnehin eher auf dem Vorgang der Bewegung zu liegen als auf dem der Ankunft, einer Bewegung, die entsprechend nicht als Progressus auf einer Zielgeraden zu denken ist, sondern als ein multiples Schweifen in Richtung des Horizonts, das sich um sein Ziel wenig kümmert - solange es nur in der Ferne liegt.

Diese Vermutungen werden in gewisser Weise bestätigt durch die zweite wesentliche Komponente der von Brentano analysierten "Empfindung." Die Erfüllung des "Anspruch[s] den das Herz macht," wird vereitelt durch einen "Abbruch ..., den Einem die Natur thut." "Muß" man, was Unfreiwilligkeit impliziert, einerseits "zurück" und bleibt damit wider Willen an das gebunden, was man flieht, so "kann" man andererseits nicht "hinüber." Und auch die "Stimme des Lebens" ist bloß Klang und Lockung, ohne daß man dieser verfiele, ohne daß die begehrte Einheit realisiert würde: Immer bleibt das Subjekt in dem Zustand, in dem es "Alles zum Leben vermißt." Das aber ist erstaunlicherweise kein Dementi des anfänglichen Ausrufs "Herrlich ist es...." Im Gegenteil: Der "Abbruch" "gehört" nicht minder als der "Anspruch" zur Empfindung des Herrlichen; in ihrem Ineinander erst konstituieren beide den Reiz der Seelandschaft, wie durch den Parallelismus der Satzkonstruktion, das anaphorische "dazu gehört," nachdrücklich unterstrichen wird. Die Bewegung von Blick und Wunsch wird so zwar in Gang gesetzt, kommt aber nicht an, ja darf das gar nicht. Sie bleibt im Flug, wird als reine Bewegung perpetuiert.

Es dürfte längst deutlich geworden sein, daß Brentano in diesen Sätzen nichts anderes tut, als einen Topos zu formulieren. Bis zum letzten Bildpartikel lassen sich seine Aussagen dem Begriff der "Sehnsucht" subsumieren - oder, wie man in dieser Zeit gern hinzufügt, der "un- 
endlichen Sehnsucht," - der im übernächsten Satz und dann noch öfter in Brentanos ursprünglichem Text fällt. ${ }^{19}$ Spätestens seit Eichendorff "das eigentliche Wesen aller romantischen Kunst" unter anderem in einer "stets unbefriedigte[n], ahnungsreiche[n] Sehnsucht" angesiedelt hat, gilt diese als 'romantisch' par excellence. ${ }^{20}$ Es ist allerdings nötig, diesen Vorstellungsnexus noch etwas genauer ins Auge zu fassen. Erst vor dem Hintergrund weiterer Texte und Überlegungen zur Sehnsucht können Brentanos Eingangssätze, und damit die Position, aus der er Friedrichs Gemälde beurteilt, ganz transparent werden. Ich beschränke mich dabei auf eine vereinfachende Strukturskizze des Problems. ${ }^{21}$

Sehnsucht ist eine spezifische Form der romantischen Utopie. Als eine dynamische Utopie tritt sie an die Stelle der statischen Raumutopie der Aufklärung, die in Staatsroman und Idyllik das realisierte Ideal des richtigen Lebens an einen Ort verlegt hatte, der zwar fiktiv war, jedoch einer 'möglichen Welt' angehörte, die sich nicht prinzipiell außerhalb des Erfahrungsraums der aufgeklärten Subjekte befand. Auch die utopische Konzeption der Sehnsucht wird räumlich inszeniert, mit Arkadien, Felsenburg oder den glückseligen Inseln aber hat das nichts mehr zu tun. Der abgeschlossene Raum der aufklärerischen Utopie wird in der Romantik aufgebrochen und dynamisiert. ${ }^{22}$ Der Held zahlreicher romantischer Erzählungen und Romane, ein Künstler oft, jedenfalls ein Antibürger, wird von einem heftigen "Ungenügen an der Normalität" des Bestehenden (Pikulik) geplagt, und dieses Leiden liegt der Sehnsucht nach einem Anderen und Besseren zugrunde. Auch dieser antibürgerliche Zug steht im Gegensatz zur Aufklärungsutopie mit ihrem dezidiert bürgerlichen Charakter. Eine leicht irritierbare, vagierende Bewegung, für die die Weite des Raums Bedingung ist, setzt nun ein, eine Bewegung weg vom Gegebenen, die, wie Heinz Hillmann gezeigt hat, zwei Richtungen nehmen kann. ${ }^{23}$ Als vertikale führt sie in die Höhe, bleibt dabei aber notwendig eine Bewegung der Phantasie, seelischer Aufschwung. Als horizontale führt sie, meist als wirkliche Reise des Helden im Raum, in die lockende blaue Ferne. Im hier verfolgten Zusammenhang ist Bewegung primär in ihrer horizontalen Erstreckung bedeutsam.

Gewiß hat schon die Aufklärung den Ausblick in die Ferne mit utopischen Vorstellungen verbunden. Rousseau zitierend, sagt etwa Christian Garve: "Der Mensch wünscht in die Ferne zu sehn..., weil ihm niemahls da wohl ist, wo er ist, und er sich immer glücklicher denkt, wenn er sich in Gedanken an einen entfernten Ort versetzt." ${ }^{24}$ So sehr diese Aussage eine Vorform des romantischen Fernemotivs darstellt, so sehr unterscheidet sie sich von diesem. Denn bei Garve/Rousseau wird gewissermaßen am anderen Ende des Ausblicks ein "Ort" des glücklichen Lebens gedacht, in den man sich, die Bewegung dorthin überspringend, "versetzt." Ein solcher Ort aber fällt in der romantischen Sehnsuchtslandschaft aus. Und das hat gute Gründe.

Bereits in Goethes Werther wird unmißverständlich ausgesprochen, daß die Reise in die Ferne illusionär ist. Die Ferne lockt zwar, sie verklärt die in ihr gelegenen, allenfalls schemenhaft wahrnehmbaren Gegenstände und regt die Phantasie an, das ersehnte Glück in ihr anzusiedeln. Wo dies aber zum Aufbruch nach den Orten und Objekten des Begehrens führt, ist nur Enttäuschung das Ergebnis. So geht es Werther, der sehnsüchtig "vom Hügel in das schöne Thal" schaut, dann jedoch feststellen muß: "Und ach! wenn wir hinzueilen, wenn das Dort nun Hier wird, ist alles vor wie nach, und wir stehen in unserer Armuth, in unserer Eingeschränktheit, und unsere Seele lechzt nach entschlüpftem Labsale." ${ }^{25}$

Mit dieser Entzauberung der Ferne hätte das Thema Fernsehnsucht erledigt sein können, noch bevor es so recht auf den Plan getreten war. Bekanntlich ist das Gegenteil der Fall. Erst die Romantiker entdecken die ihm innewohnenden Möglichkeiten und loten es in allen Dimensionen aus. Werthers Erfahrung bleibt den romantischen Reisenden dabei freilich so gut wie nirgends erspart. Die Enge und Unzulänglichkeit des Bestehenden heften sich an ihre Fersen, und daher verwandelt sich der Gegenstand der Sehnsucht, sobald man ihn erreicht, aus 
einem geheimnisvoll auratischen Ideal wieder ins schlechte Gegebene. Im Grade der Annäherung ans Begehrte weicht die verklärende Qualität der Ferne von ihm und hinterläßt es nackt und nichtig. Jede nähere Bekanntschaft mit dem Idealisierten entkleidet dieses aller Idealität. Ständig zieht sich die Ferne vor dem Wanderer zurück, nimmt den schönen Schein mit sich und wirft ihn neuen Gegenständen über. Diese werden nun zum Ziel des Helden, um unweigerlich dem Geschick ihrer Vorgänger zu verfallen, sofern sie in Besitz genommen werden. Ein endloser Iterationsprozeß setzt ein, eine Jagd nach dem Glück, das immer anderswo ist, eine Flucht der Objekte des Begehrens, die nicht selten mit den Qualen des Tantalus verglichen wird. ${ }^{26}$

In zahlreichen Variationen hat die romantische Literatur diesen Prozeß durchgespielt. Seinen Niederschlag findet er in Tiecks Sternbald ebenso wie in Brentanos Godwi oder in Eichendorffs Ahnung und Gegenwart. ${ }^{27}$ Die Romantiker bleiben allerdings beim Wissen um das Ungenügen an Gegenwart und Besitz des ersehnten Objekts nicht stehen. Vielmehr provoziert dieses verschiedene Antworten und generiert dabei mehrere Formen des Handlungsverlaufs.

Eine höchst fatale Wendung nimmt das Geschehen, wo sich die Enttäuschung über die Kluft zwischen der idealisierenden Vorstellung des ersehnten Gegenstands und seiner endlichen Realität in Aggression gegen ihn umsetzt. Dies ist etwa bei E.T.A. Hoffmanns Don Juan der Fall, dem in der ständigen Abfolge von Begehren und Ernüchterung "alles irdische Leben matt und flach" wird, so daß er sich schließlich "gegen die Erscheinung" auflehnt, "die ihm das Höchste im Leben geltend, so bitter ihn getäuscht hatte." ${ }^{28}$ Der Besitz einer Frau dient von nun an nur noch ihrer Zerstörung. Abwandlungen dieser Thematik finden sich häufig in Hoffmanns Werken. Ihre dominante Form wird mit unerbittlicher Konsequenz im Nachtstück Die Jesuiterkirche in G. entfaltet. Die für die Künstlerlaufbahn des 'Helden' konsumtive Idealisierung einer Frau, in der die Sehnsucht nach einem utopischen "Höheren" Gestalt und Ziel gewinnt, wird zerstört durch die Ehe mit dieser. Die reale Person der Geliebten, die nur den Projektionsschirm der Innenwelt des Künstlers abgeben dürfte, drängt sich an die Stelle des Phantasiebildes, das das sehnsüchtige Subjekt von ihr hatte. Um die Idealisierung und damit die Fähigkeit zur Kunst zu bewahren, "entledigt" sich der Maler Berthold seiner Frau - wie es scheint, durch Mord. ${ }^{29}$

Harmlos ist demgegenüber eine andere Variante: der Stillstand der als sinnlos erkannten Bewegung. In Tiecks Sternbald etwa bekennt der aus Ägypten, dem Land der Geheimnisse, zurückgekehrte Ludoviko nach einschlägigen Erfahrungen: "Das Lächerlichste an mir ist, daß ich nicht immer an demselben Orte bleibe. ${ }^{30}$. Diese Folgerung hatte sich früher schon dem Protagonisten von Tiecks Roman William Lovell aufgedrängt. Das Streben in die Ferne und seine Vergeblichkeit äußern sich dort in den Worten: "Ich möchte in manchen Stunden von hier reisen und eine seltsame Natur mit ihren Wundern aufsuchen ... o Rosa, wohin mit dieser Ungenügsamkeit? und würde sie mir nicht selbst zum Orkus und in Elysium folgen?" ${ }^{31}$ Aufgrund dieser Antizipation bricht Lovell - jedenfalls an dieser Stelle - gar nicht erst auf. Verneint wird allerdings nicht Bewegung überhaupt, sondern nur die in der Horizontalen. Lovells Motorik richtet sich statt dessen in die Höhe, ist "seelische Schwärmerei, die alle realen Genüsse der Welt durch Exaltationen der Phantasie immer weiter zu treiben sucht."'32 Doch der Aufflug birgt gleichfalls Gefahren: Stößt er einerseits ins Leere vor, so bedroht er andererseits mit dem Absturz, der sich fast zwingend aus dem affektiven Haushalt der Phantasie ergibt und eine Situation herbeiführt, die schlimmer ist als je zuvor. ${ }^{33}$ Die vertikale Bewegung ist damit jedoch ebensowenig erledigt wie die horizontale durch Werthers Leiden an ihr. Bei Eichendorff, auch bei Hoffmann, erhält sie neuerlichen Auftrieb, wenn auch unter anderen Voraussetzungen. Eichendorffs Friedrich läßt sich, nachdem seine (horizontale) Reise einen Kreis beschrieben hat, im Kloster nieder. Wiederum aber bedeutet dies keinen völligen Stillstand, sondern eine Umpolung von Bewegung. Diese schlägt nun in eine vertikale um, die sich im 
Gegensatz zum frühen Tieck durch das Netz der positiven Religion vor Leere und Absturz gesichert darstellt. Friedrich entsagt dem irdischen "Plunder" und wendet sich zu Gott. ${ }^{34}$

Die religiöse Wendung am Schluß von Ahnung und Gegenwart berührt sich in manchem mit einem weiteren Modell, das das für die Romantik eigentlich maßgebliche ist. Die Varianten der ernüchterten Sehnsucht - Destruktion und völliger Stillstand - bilden gewöhnlich nur den düsteren Fond, von dem es sich abheben soll. Diese negativen Konsequenzen werden hier dadurch vermieden, daß eine Begegnung mit dem begehrten Objekt gar nicht erst stattfindet. Die Sehnsucht muß als ein endloses Streben nach einem Unerreichbaren verewigt werden. Dann nämlich bleiben die Euphorie des Aufbruchs und die Vorstellung eines unermeßlichen Glückszustands bestehen, die sonst in der Abfolge immer neuer Enttäuschungen unweigerlich zerrieben würden. Das Ersehnte muß sich als ein Fernes erhalten, und wenn es nicht mit dem Horizont vor dem Betrachter zurückweicht, so muß dieser es mit Eile passieren. Die größte Lust jedenfalls bereitet das "Vorbeifliegen am Gegenstand." ${ }^{35}$ Ganz in diesem Sinne sagt ein Ausstellungsbesucher in Brentanos ursprünglicher Besprechung des Mönchs am Meer:

O, ich wollte, ich wäre der Kapuziner, der so ewig einsam hinüberschaut in das dunkle verheißende Meer, das wie die Apokalypse vor ihm liegt, so wollte ich mich ewig sehnen nach Ihnen, liebe Julie, und Sie ewig vermissen, denn diese Sehnsucht ist doch die einzige herrliche Empfindung in der Liebe. ${ }^{36}$

Hinter dieser Lösung verbirgt sich freilich eine weitere Einsicht, zu der die glücklicheren der romantischen Helden auch vordringen. Da alle erreichbaren Gegenstände, Frauen und Landschaften nur neuerliche Unzufriedenheit bewirken, wird deutlich, daß sich die Sehnsucht in letzter Konsequenz überhaupt nicht mehr auf Benennbares richtet. Alles Konkrete, was den romantischen Helden vom Schauplatz seiner alltäglichen Leiden lockt, hat nur die Funktion eines Auslösers einer prinzipiell unabschließbaren Bewegung. Die vom Ungenügen am Gegebenen hervorgerufene sehnsüchtige Imagination bedarf einer Folie, auf die sie sich projizieren, eines Gegenstands, um den sie sich kristallisieren kann. Dieser aber ist nicht selbst 'gemeint'; er ist nicht das eigentliche Ziel der Sehnsucht, sondern lediglich ein Platzhalter, ein Wegweiser zu etwas anderem, dessen Symbol.

Es lag in allen seinen Bildern eine geheime Sehnsucht nach irgend einem andern Gegenstande, und es war mir oft vor ihnen, als sagten sie mit dunkeln unverständlichen Worten: 'Wir sind die wahren nicht'; sie schienen ewig zu entfliehen, um höhern Wesen die Stelle zu räumen, oder standen ängstlich da, als ständen sie nicht an der rechten Stelle. ${ }^{37}$

Die ganze Flucht der Stellvertreterobjekte und Symbole wird schließlich transparent auf ein schlechthin Anderes, das das letzte Ziel der Sehnsucht ist. Sofern es sich dabei nicht wie bei Eichendorff um die Sphäre religiöser Transzendenz handelt, ${ }^{38}$ kann dieses Andere allenfalls in vagen, mitunter auch ein wenig hilflosen Formulierungen umkreist werden, die immer in der Gefahr schweben, seinen tatsächlichen Charakter, das unaussprechliche Anderssein, zu verdunkeln. Deutlich aber ist, daß die romantische Utopie der Sehnsucht zur Leere tendiert. Um zu bezeichnen, was nicht zu bezeichnen ist, bedient sich etwa E.T. A. Hoffmann häufig der Formel vom "Höheren" oder vom "unbekannten Etwas. ${ }^{39}$

Im Zusammenhang mit Brentanos Sätzen über den Reiz der Aussicht auf das Meer ist es von besonderer Bedeutung, daß das Ziel der Sehnsucht oft mit dem "Leben" selbst identifiziert wird, das als "ein schönes, überschwenglich reiches Geheimnis" in der Ferne lockt. ${ }^{40}$ Und auch Vorstellungen von Ich-Entgrenzung und All-Einheit begegnen dabei häufig, obwohl man ja zunächst vermuten könnte, daß sie mit dem Motiv der Ferne, die vom Betrachter per definitionem durch Distanz getrennt ist, unverträglich seien. Das ist jedoch nicht der Fall. Beginnend mit Werthers pantheistisch instrumentierter Sehnsucht, sich in die überschaute "weite Gegend" zu "verlieren," ${ }^{11}$ finden sich beide Motive vielfach verknüpft, beispielsweise 
in Novalis' Heinrich von Ofterdingen, wo dieser sich in die "blaue Flut" der "Ferne" "tauchen" möchte. ${ }^{42}$

Der scheinbare Widerspruch löst sich leicht. Denn natürlich trifft auf Entgrenzung und Einheit mit der Natur zu, was für alle anderen Gegenstände der Sehnsucht auch gilt: Im gegebenen Zustand, der durch Begrenzungen und Entzweiung bestimmt ist, sind sie immer abwesend und können nur als jenseits seiner, in der Ferne liegend imaginiert werden. Das Fernemotiv drückt also den Wunschcharakter der Einheitsvorstellungen aus, aber nicht nur ihn. Wiederum nämlich gilt auch für diese, daß die Qualität der Ferne ihnen dauerhaft zukommen muß: Als bloßes Phantasma sind sie lustvoll, als realisierte aber würden sie nicht nur wie die Stellvertreterobjekte der Sehnsucht allen Reiz verlieren, sie wären geradezu die Zerstörung ihres Subjekts. Nur selten läßt die romantische Literatur Zweifel an der Ambivalenz der 'dionysischen' Sehnsucht nach Auflösung und All-Einheit, die gleichermaßen höchste „Lebenslust“ in der Entäußerung wie tödliche Bedrohung durch die „Vernichtung“ des Individuums wären. ${ }^{43}$ Es ist daher sehr plausibel, daß Brentano in der Friedrich-Besprechung den "Abbruch" an seinem "Anspruch" als konstituierenden Bestandteil der Herrlichkeit des Ausblicks auf den Ozean nennt. Auch wenn es einen Modus gäbe, Entgrenzung ohne die Komponente der Vernichtung zu denken, so wäre allein schon die Vorstellung einer Ankunft am Ziel der Wünsche hinreichend, das romantische Subjekt erschauern zu machen und die Forderung des "Abbruchs" zu begründen. Denn wie die Ferne darf selbst das letzte Ziel der Sehnsucht, das schlechthin Andere, niemals als ein erreichtes gedacht werden, wäre es doch als solches gerade nicht mehr das ersehnte Andere; sogar "in Elysium" würde daher die "Ungenügsamkeit" fortdauern, wie im William Lovell zu erfahren war. Das Andere kann damit nur noch im Bild einer ständigen Bewegung auf es zu ersehnt werden, einer Bewegung, die das Gegebene hinter sich läßt, sich von dem trügerischen Schein der Stellvertreterobjekte ziehen läßt, aber unbeirrt an allem Begehrten vorbeifliegt. Bewegung selbst wird so zum Modus und eigentlichen Inhalt der Sehnsucht.

Es ist daher nicht erstaunlich, daß Sehnsucht in der Romantik so oft als selbstbezüglich charakterisiert wird. Wenn der Sehnsucht Schritt für Schritt alle Gegenstände entzogen werden, sie zugleich aber die einzige Möglichkeit bleibt, das schlechte Bestehende zu transzendieren, dann muß es darauf ankommen, sie so lange wie möglich in der Schwebe zu erhalten. Sehnsucht richtet sich dann auf sich selbst und ihre Verewigung als ein Medium der Transgression und eines wie auch immer indirekten und minimalisiertcn 'Rapports' mit dem Utopischen. In Tiecks Phantasus heißt es darum:

... ja, es gibt... eine Sehnsucht, die ewig währt, weil sie ewig nicht erfüllt wird; weder getäuscht noch hintergangen, sondern nur nicht erfüllt, damit sie nicht sterbe, denn sie sehnt sich im innersten Herzen nach sich selbst.. ${ }^{44}$

Der Sehnsucht fällt die Erbschaft jener Aura zu, die früher die konkreten Gegenstände der Utopie verklärt hatte, die nun ausgefallen sind.

Es liegt auf der Hand, daß diese Konzeption der Sehnsucht außerordentlich labil ist. Auf allen ihren Stufen wird sie vom Umschlag in den Nihilismus gefährdet. Das ist nicht nur dort der Fall, wo Erfüllung von den ersehnten Gegenständen erwartet wird und der daraufhin einsetzende Kreislauf von Begehren und Ernüchterung schließlich die ganze Bewegung, und Hoffnung überhaupt, als nichtig entlarvt. "Alles ist Einbildung," weiß Leontin in Ahnung und Gegenwart. ${ }^{45}$ Vom Verdikt der bloßen Einbildung bleibt aber auch die "unendliche Sehnsucht" bedroht. Darf deren Ziel weder als konkret noch als erreichbar vorgestellt werden, so ergeben sich doch die größten Schwierigkeiten, wenn es nicht als in irgendeiner Weise 'objektiv' gedacht werden kann. Wo der perpetuierte Schwebezustand der Sehnsucht sich ohne Bezug auf eine externe Sinndimension bloß als Produkt der Phantasie begreifen muß, da steigt 
und fällt er mit der Dignität und Verbindlichkeit, die dieser beigelegt werden. Der akute Kollaps droht ihm, sobald subjektive Innenwelten lediglich als Reich des Chimärischen betrachtet werden. Der Ausblick in die verklärende Ferne kippt dann um in den Anblick von Leere und Nichts. ${ }^{46}$ Nihilismus ist die Kehrseite der romantischen Sehnsucht.

II.

An dieser Konzeption von Sehnsucht, die in nuce in den Eingangssätzen seiner Besprechung enthalten ist, mißt Brentano das Gemälde Caspar David Friedrichs. Die kompakte kleine Analyse der Empfindungen angesichts der Weite des Ozeans setzt das Kriterium frei, an dem die künstlerische Darstellung dieses Sujets ihre Qualität zu erweisen hat.

Anknüpfend an die Aussagen über die Gleichzeitigkeit von "Anspruch" und "Abbruch" verkündet der nächste Satz lapidar und ohne weitere Begründung: "Dies aber ist vor dem Bilde unmöglich ...." Angesprochen ist offenbar der Rezeptionsakt: Die für die 'unendliche Sehnsucht' konstitutive Spannung von "Anspruch" und "Abbruch" stellt sich "vor dem Bilde" nicht ein, Sehnsucht wird in dessen Betrachter nicht erweckt. Unklar bleibt allerdings, ob diese Feststellung allein den Mönch am Meer charakterisieren soll oder ob mit dem "Bilde" nicht das Medium "Gemälde" überhaupt gemeint ist. In diesem Fall wäre von einer fundamentalen Differenz von Urbild und Abbild, Natur und Kunstwerk die Rede, und das könnte im Kontext der romantischen Abwendung vom Grundsatz der Naturnachahmung durchaus plausibel scheinen, in deren Konsequenz ja auch der empfindsame Versuch, die Gefühlswirkungen der realen Gegenstände durch die Kunst zu reproduzieren, hinfällig wird. Sowenig es auf der anderen Seite einleuchten will, daß Sehnsucht als Wirkung von Gemälden "unmöglich" sein sollte, so wenig Indizien gibt es überdies, daß Brentano seine Bildbesprechung ins Prinzipielle wenden wollte, zumal die parallele Anordnung der Präpositionen "vor," "in" und "zwischen" auf ein gemeinsames Objekt, Friedrichs Gemälde nämlich, verweist. Warum dieses Sehnsucht nicht evozieren kann, wird in den folgenden Gliedern der Satzreihe deutlich, in denen Brentano seine Erwartung dem Bild gegenüber formuliert.

Was er "in dem Bilde selbst," also wohl auf der Gegenstandsebene, finden will - die normative Dimension wird dabei durch das "sollte" markiert -, ist genau die genannte Spannung von Anspruch und Abbruch. Mit anderen Worten : Brentano erwartet von dem Bild, daß es Sehnsucht darstellen solle - eine Forderung, die augenscheinlich weniger von der bildenden Kunst als von der romantischen Literatur her entwickelt wird, die ja seit ihren Anfängen Sehnsucht thematisiert und geradezu zum strukturbildenden Element erhoben hatte. Brentano aber findet nicht, was er sucht; sein "Anspruch" an das Bild läuft ins Leere, dieses tut ihm daher "Abbruch." Damit ist ein Defizit angezeigt; in äußerster Kürze wird Kritik geübt. In dieser auf denkbar knappem Raum vollzogenen Wendung verschiebt sich nun allerdings die Bedeutung der Begriffe "Anspruch" und "Abbruch" in eklatanter Weise, und dies führt zu einer besonderen Schwierigkeit beim Verständnis des Texts. Denn wurden "Anspruch" und "Abbruch" als Konstituentien der sehnsüchtigen Empfindung vor der Weite des Meeres eingeführt, erscheinen sie sodann als potentielle Gegenstände des Bildes, so werden sie jetzt quasi kunsttheoretisch gewendet und charakterisieren den Bereich der 'Interaktion' "zwischen" dem Kunstwerk und seinem Betrachter: dessen ästhetische Erwartungen und die 'Antwort' des Artefakts auf sie. Zugegebenermaßen ist diese Trennung der Bedeutungsschichten ein Akt interpretatorischer Rekonstruktion, der erforderlich ist, weil Brentano und Kleist selbst diese Schichten um der Eleganz der Formulierung willen bedenkenlos ineinander schieben. In Brentanos ursprünglichem Text ist folgendes zu lesen: " ... und das, was ich in dem Bilde selbst finden sollte, fand ich erst zwischen mir und dem Bilde, nämlich einen Anspruch, den 
mir das Bild that, indem es denselben nicht erfüllte..." (GS, 424). Kleist hat offenbar die Notwendigkeit, hier klärend einzugreifen, gesehen, das eigentliche Problem aber durch seine Redaktion nicht behoben: "... und das, was ich in dem Bilde selbst finden sollte, fand ich erst zwischen mir und dem Bilde, nehmlich einen Anspruch, den mein Herz an das Bild machte, und einen Abbruch, den mir das Bild that...." Beide Varianten formulieren indes ein Unmögliches. Denn undenkbar ist, daß bereits "in dem Bilde selbst" enthalten sei, was doch erst dem Bereich der Auseinandersetzung mit ihm zugehört: die Spannung zwischen der ästhetischen Erwartung und ihrer Enttäuschung durch das Werk. Bei der Relation von "Anspruch" und "Abbruch," die "zwischen" Betrachter und Bild lokalisiert wird, handelt es sich also offensichtlich - und das wird durch die verknappte Formulierung verschleiert - um eine ganz andere als die, die Brentano "in dem Bilde selbst" finden wollte.

Um es noch einmal weitläufig zu reformulieren: Was Brentano im Bild dargestellt sehen will, ist im Sinne der Sehnsuchtskonzeption "ein Anspruch, den das Herz macht, und ein Abbruch ..., den Einem die Natur thut." Diesen ästhetischen "Anspruch" Brentanos aber erfüllt das Bild nicht und tut dem Beschauer insofern "Abbruch."

Es erweist sich dabei jedoch eine abstrakte Gemeinsamkeit zwischen dem Bildbetrachter und dem realen Betrachter des Ozeans, der in Friedrichs Gemälde in Gestalt des Mönchs dargestellt wird. So sehr sich die Positionen beider auch unterscheiden, so sehr wird mit dem jeweiligen Vorliegen eines Verhältnisses von "Anspruch" und "Abbruch" doch ihre strukturelle Homologie betont: "und so ward ich selbst der Kapuziner...." Nur auf den ersten Blick mag es naheliegen, diesen Satz nach dem Vorbild einer Auffassung zu lesen, die in der kunsthistorischen Forschung verbreitet ist. Die Rückenfiguren Caspar David Friedrichs sind demnach Repräsentanten des Bildbetrachters, der dazu bewegt werde, "sich in die Figur und das sich ihr bietende Erlebnis hineinzuversetzen." ${ }^{47} \mathrm{Da}$ bei Brentano ein auf dieser Basis sich vollziehender Identifikationsakt gemeint sei, läßt sich jedoch aus dem Text nicht belegen. ${ }^{48}$ Wenn hier das Ich zum Kapuziner wird, so geschieht dies, wie der kausale Anschluß "und so" zeigt, ausdrücklich allein aufgrund der genannten Strukturhomologie, die wohlgemerkt keine inhaltliche Gleichheit der Empfindungen ist. In der äußeren Natur nämlich ist das Spannungsverhältnis von Anspruch und Abbruch konstitutiv für das "herrliche" Gefühl der Sehnsucht, angesichts des Bildes aber indiziert es lediglich ein Defizit, das Enttäuschung und Kritik hervorruft.

Es ist daher bildlogisch völlig plausibel, daß im folgenden eine bezeichnende Verwerfung in der Entsprechung von Kapuziner und Bildbetrachter eintritt. Der Mönch blickt aufs Meer, der Ausstellungsbesucher auf das Gemälde, so daß in der Fortführung ihrer Homologie Meer und Gemälde einander korrespondieren müßten. Statt dessen aber heißt es: "das Bild ward die Düne," und das ist ganz folgerichtig, wenn man bedenkt, was die Düne für den realen Naturbetrachter bedeutet. Der Ozean, auf den dieser blickt, löst Sehnsucht aus bzw. aktiviert sie, die Düne hingegen ist der Standpunkt, von dem aus der sehnsüchtige Blick geworfen wird. In dieser Eigenschaft gehört sie jenem Bereich des Gegenwärtigen und Gegebenen zu, den die Sehnsucht gerade zu überschreiten strebt, jenem Bereich des Ungenügens, an den das Subjekt unauflöslich gefesselt ist. Die Düne ist ein Ort des Defizits und des "Abbruchs" an allen utopischen Ansprüchen. Wenn sie als Metapher für das Gemälde adäquat scheint, so wird damit vehementer Einspruch gegen dieses laut. Was vorher begrifflich ausgedrückt wurde, wird nun in ein Bild gefaßt und dadurch zugleich radikalisiert. Denn daß das Gemälde zur Düne wird, heißt nicht bloß, daß es "Abbruch" ist, Abbruch am ästhetischen Anspruch seines Betrachters; in diesem Versagen wird es selbst geradezu zum Teil des schlechten Gegebenen. Den Grund dafür umschreibt der nächste Satz: "das aber, wo hinaus ich mit Sehnsucht blicken sollte, ${ }^{49}$ die See, fehlte ganz." Konsequenterweise zeigt sich dort, wo in der eigentümlich verschobenen metaphorischen Parallelisierung von Kapuziner und Bildbetrachter der Ozean zu stehen hätte, 
bloße Leere. Wenn der Betrachter durch Struktur-gleichheit zum Kapuziner wird, das Gemälde aber nicht zur See, sondern zur Düne, dann muß der Blick des Betrachters, der ja auf der Düne steht, die das Bild ist, notwendig in den Bereich hinter diesem fallen. Dort aber ist Nichts. Der reale Ozean, Bild utopischer Verheißung, findet keinerlei Entsprechung in der Situation des Ausstellungsbesuchers, der das Gemälde als puren "Abbruch" an seiner Erwartung, Sehnsucht dargestellt zu sehen, empfindet, ihm damit jede transzendierende Potenz abspricht und ihm allein den Status der Negativität der Düne zuweist. Der dabei leise, doch unüberhörbar mitklingende Verdacht des Nihilismus erklärt sich aus dem besonderen Stellenwert, der der Sehnsucht beigemessen wird. In einer historischen Situation, in der alle konkreten, benennbaren und realisierbaren Vorstellungen als Träger utopischer Hoffnung problematisch werden, zieht diese sich, wie die obige Strukturskizze zu zeigen versuchte, auf die selbst prekäre, instabile Bewegung der Sehnsucht zurück. Sehnsucht wird zu einem der letzten Refugien des Utopischen. Brentanos ästhetischer "Anspruch" ist daher nicht ein beliebiger Wunsch nach einem beliebigen künstlerischen Sujet, sondern fordert genau eine das Gegebene transzendierende Funktion des Kunstwerks. Daß Caspar David Friedrich ausgerechnet bei der Behandlung eines Gegenstands, der nicht nur in Brentanos Augen so ungemein eng mit der Empfindung der Sehnsucht verknüpft war, auf deren Thematisierung zu verzichten schien, mußte unter diesen Bedingungen geradezu wie eine prinzipielle Leugnung der utopischen Dimension sowohl des dargestellten Sujets als auch des Kunstwerks wirken, wie eine Absage ans Utopische überhaupt. Eine solche Verneinung der Möglichkeit, das schlechte Gegebene auf ein Anderes hin zu übersteigen, handelt sich leicht den Vorwurf nihilistischer Verzweiflung ein. Ihm scheint Friedrichs Gemälde verfallen zu sein, in dem nach Brentanos Meinung an die Stelle der utopischen Dimension, verbildlicht in der "See," eine völlige Leere tritt: das Nichts. Blickt man von hier aus noch einmal zurück auf den Satz "Dies aber ist vor dem Bilde unmöglich," so wird allerdings plausibel, daß ein Werk, dem derartiges zur Last gelegt wird, Sehnsucht nicht zu evozieren vermag - allenfalls die, daß es doch anders wäre, nämlich dem "Anspruch" seines Betrachters gemäß. ${ }^{50}$

Man wird sich fragen, ob und inwieweit Brentanos Rezeption des Gemäldes von diesem her begründet und nachvollziehbar ist. Könnte man nicht mit gutem Recht die Auffassung vertreten, der Mönch am Meer habe durchaus Sehnsucht zum Thema? Kommt denn nicht gerade Friedrichs innovatorische Verwendung der Rückenfigur, kommt nicht die Placierung eines einsamen Subjekts vor der Unermeßlichkeit der Natur, in die es hinausblickt, der Forderung Brentanos entgegen, das Bild solle die aus "Anspruch" und "Abbruch" amalgamierte Sehnsucht selbst - nicht also beliebige Gegenstände der Sehnsucht - darstellen? Die kunsthistorische Forschung hat verschiedentlich bemerkt, daß die Landschaft in Friedrichs Gemälden sich nicht mehr wie in der Tradition der Landschaftsmalerei als ein offener, frei begehbarer Raum präsentiere und daß statt dessen ein "Pathos der Distanz" die Bildgestaltung präge. ${ }^{51}$ Das kommt nicht zuletzt in den Rückenfiguren zum Ausdruck, die vom Gegenstand ihrer kontemplativen Anschauung unaufhebbar getrennt sind und die "Natur als Metapher dessen, was ihnen versagt ist," erfahren. "Im Kunstwerk versammelt sich demnach, in Gestalt der Landschaft, die Einsicht in die Unversöhntheit des menschlichen Daseins: es ist das Gegenbild, das diesen Bruch weder heilt noch überwindet, sondern sichtbar und damit bewußt macht," wie Werner Hofmann ausführt. Friedrichs Landschaften sind Bilder radikaler Entzweiung, die "keine vollzogene, höchstens eine erhoffte Versöhnung" erkennen lassen. ${ }^{52}$ Brentanos Forderung könnte in einer solchen Bildkonzeption durchaus ihre adäquate Verwirklichung finden. Denn Entzweiung ist die Bedingung der Sehnsucht - nicht nur, insofern sie diese allererst hervortreibt, sondern auch, weil sie als konstitutiver "Abbruch" die Erfüllung verhindert - und muß als diese Bedingung die Darstellung von Sehnsucht maßgeblich bestimmen.

Freilich reicht das nicht aus. So sehr die romantische Sehnsucht zur Gegenstandslosigkeit 
neigt und ihre eigene Unerfüllbarkeit einschließt, so sehr scheint sie der Bilder von Positivität zu bedürfen. Die Gestaltung von Entzweiung im Kunstwerk bleibt Darstellung bloßer Negativität, solange nicht irgendwo die Idee von deren Transgression aufscheint. So verhält es sich offenbar mit der Aufnahme des Mönchs am Meer. Das Individuum vor der Unendlichkeit der Natur konnte nicht als Bild von Sehnsucht 'gelesen' werden, da die Trostlosigkeit der Trennung noch die Darstellung dessen tingiert, was innerhalb des Bildes allein Gegenstand der Sehnsucht sein könnte. In der Tat zeigt die Geschichte der Rezeption, daß das Gemälde nicht bloß in allgemeiner Weise als zu traurig und hoffnungsleer empfunden, sondern daß gerade das Fehlen positiver Zeichen beanstandet wurde. Brentano, der selbst dem Bild die utopische Dimension abstreitet, läßt eine Dame vor dem Gemälde sagen: "nur wünschte ich, daß eine frische Seeluft wehte und ein Segel herantriebe, und daß ein Sonnenblick niederglänzte und das Wasser rauschte... ." ${ }^{53}$ Die Dame dürfte getroffen haben, was viele Betrachter zurückschreckte. Marie Helene von Kügelgen jedenfalls hat es ähnlich ausgedrückt:

Der Himmel ist rein und gleichgültig ruhig, kein Sturm, keine Sonne, kein Mond, kein Gewitter - ja, ein Gewitter wäre mir ein Trost und ein Genuß, dann sähe man doch Leben und Bewegung irgendwo. Auf der ewigen Meeresfläche sieht man kein Boot, kein Schiff, nicht einmal ein Seeungeheuer, und in dem Sande auch nicht ein grüner Halm. Nur einige Möwen flattern umher und machen die Einsamkeit noch einsamer und grausiger. ${ }^{54}$

Derartige Einwände sind immer wieder gegen manche Bilder Friedrichs erhoben worden nicht freilich gegen solche vom Schlage der Frau in der Morgensonne ${ }^{55}$ (Abb. 2), die dem "Anspruch" des Runge-Verehrers Brentano ungleich besser Genüge getan hätte. Nur um Haaresbreite scheint die Abtei im Eichwald, ${ }^{56}$ die zusammen mit dem Mönch am Meer ausgestellt wurde, dessen Schicksal entgangen zu sein. Johanna Schopenhauer hat sich folgendermaßen zu ihr geäußert: "Welch ein Bild des Todes ist diese Landschaft! Wie schauerlich, wie hoffnungsleer ohne den ewigen Stern der Liebe, der oben blinket." ${ }^{57}$ Die Reihe gleichartiger Zeugnisse ließe sich vermehren. ${ }^{58}$ Ein Stern, ein Schiff also



Abb. 2: Caspar David Friedrich, Frau in der Morgensonne

würden genügt haben, den Gehalt des Mönchs am Meer grundlegend zu verändern. Durch ein bescheidenes Zeichen, durch einen minimalen Abstand können die Bilder von Trost und Hoffnungslosigkeit, von erfüllter Unendlichkeit und leerem Nichts voneinander getrennt sein. Erneut zeigt sich die Nähe von Sehnsucht und Nihilismus, die Leichtigkeit, mit der jene in diesen umschlagen kann. Es ist höchst aufschlußreich, daß derartige Zeichen auf früheren Fassungen des Mönchs am Meer enthalten waren. Ein Besucher von Friedrichs Atelier beschreibt das Sujet des Gemäldes als "die Ostsee mit schön blinkenden Wellen beim letzten Viertel des Mondes und dem schwach blitzenden Morgenstern," ${ }^{59}$ und auf Infrarotaufnahmen 
zeigen sich zwei Segelschiffe zur Rechten und Linken des Mönchs. ${ }^{60}$ Wieviel konventioneller das Gemälde mit solchen Gegenständen gewirkt haben muß, erweist sich schon daran, daß es in dieser Fassung den Erwartungen seiner Kritiker entsprochen hätte. Es zeugt von Methode, daß Friedrich alle diese positiven Bildzeichen, die von einer traditionellen christlichen Ikonographie her hätten entziffert werden können, vor der öffentlichen Ausstellung des Gemäldes übermalt hat. Ganz gezielt hat Friedrich den Zustand hergestellt, der die Betrachter so erschreckte. So gesehen dürften Brentanos Bemerkungen, die freilich ein Defizit kritisieren wollen, der Intention des Malers durchaus nahekommen.

III.

Der Satz, der in der Metapher der fehlenden See kulminiert, ist der letzte, den Kleist vollständig aus Brentanos Vorlage übernahm. Dort hatte er die einleitende Reflexion beschlossen; im folgenden war Brentano zu den ironischen Dialogen unter den Besuchern der Ausstellung übergegangen, die jedoch nicht mehr Gegenstand dieser Untersuchung sein sollen. Kleists eigenständige Weiterführung der Besprechung, die freilich immer wieder kleinere Anleihen bei Brentano nimmt, knüpft, so scheint es, mit dem Demonstrativpronomen "diese" nahtlos an den vorgegebenen Text an und setzt seine Argumentation fort. Der Eindruck aber trügt. Zunächst einmal ist nämlich unklar, worauf der Rückbezug "diese Stellung in der Welt" eigentlich verweist, und diese Frage läßt sich auch mit Hilfe des Kontexts nicht eindeutig lösen. Ist man anfänglich vielleicht eher versucht, "diese Stellung" als die des dargestellten Naturbetrachters zu identifizieren, so empfiehlt es sich bei näherer Untersuchung, die eindeutige grammatikalische Relation ernstzunehmen, die auf den Bildbetrachter deutet. ${ }^{61}$ Dessen Situation wird von Kleist jedoch letztlich in ganz anderer Weise gefaßt als von Brentano. Zwar scheinen durchaus Überschneidungen vorzuliegen: Die von Kleist genannte Traurigkeit, die dann noch einmal durch den Hinweis auf Youngs "Nachtgedanken" unterstrichen wird, die Assoziation des Todes und das Gefühl des Eingeschlossenseins im "einsamen Kreis" ließen sich in der Tat als Charakteristika der "Stellung" des Bildbetrachters verstehen, wie sie Brentano begründet hat - als Charakteristika einer Situation, die bestimmt ist durch den Ausfall, ja die Leugnung einer transzendierenden Bewegung im Gemälde. Die Utopielosigkeit des Bildes drückt auf die Stimmung und damit auf das gesamte aktuelle Weltverhältnis des Betrachters. Kleists Metaphern und emotionale Valeurs können also im Sinne Brentanos begriffen werden - sie müssen es aber nicht. Denn andererseits ist es auffällig, daß von dem zentralen Gedanken, den Brentanos Text ausspricht, bei Kleist nicht einmal mehr andeutungsweise etwas zu vernehmen ist. Statt dessen tritt immer deutlicher eine völlig anders geartete Betrachtungsweise hervor, beginnend mit der Brentano entlehnten (GS, 426), aber ganz anders gewendeten Metapher vom "einsamen Mittelpunkt im einsamen Kreis" und gipfelnd in jenem berühmten, vielzitierten Bild, das ebenso enigmatisch vor den Augen der Interpreten liegt wie Friedrichs Gemälde vor denen der beiden Dichter: "... und da es [das Gemälde], in seiner Einförmigkeit und Uferlosigkeit, nichts, als den Rahm, zum Vordergrund hat, so ist es, wenn man es betrachtet, als ob Einem die Augenlieder [!] weggeschnitten wären."

Das Fehlen eines Vordergrunds, der dem Gemälde selbst zugehörte, bewirkt beim Betrachter das Gefühl, als fehlten ihm die Augenlider. Augenlider aber begrenzen zum einen das Blickfeld, zum ändern schützen sie das Auge. Beide Funktionen scheinen vor dem Mönch am Meer außer Kraft gesetzt zu sein, und dies wird ins Bild einer peinlichen Bedrohung und blutigen Verletzung gekleidet. Ob sich darin, wie bei Brentano, Vorbehalt und Kritik am Gemälde ausdrücken oder nur höchste Irritation, mit ebensolcher Faszination amalgamiert, ist schwer zu entscheiden. Jedenfalls aber ist das 'Manko,' von dem Kleist ausgeht, ein anderes 
als für Brentano: Es ist das Fehlen des Vordergrunds, das wohl auch den Eindruck der "Uferlosigkeit" bedingt, und damit wiederum die Raumkonzeption und -wirkung des Gemäldes.

Daß Kleist sich hiervon so befremdet und beunruhigt zeigt, ist die Reaktion auf die Verletzung eines Prinzips, das für die Wahrnehmungs- und Kunstgeschichte der frühen Neuzeit und speziell des 18. Jahrhunderts von größter Bedeutung war: des Prinzips der Rahmenschau. Wie August Langen nachgewiesen hat, etabliert sich im Zusammenhang mit dem Interesse an rationaler Durchdringung der Welt eine "Kunst des Sehens," die auf objektiv 'richtige' Aufnahme und Wiedergabe der Gegenstände zielt und den Sehakt daher purifizierenden Beschränkungen unterwirft. Das Sehen soll im Zeichen seiner Verpflichtung auf Präzision, Klarheit und Deutlichkeit neu gelernt werden, und daraus ergibt sich die "Tendenz, den jeweiligen Apperzeptionspunkt, den kleinen Ausschnitt der schärfsten und deutlichsten Wahrnehmung abzusondern, einzufassen und losgelöst zu betrachten. Dadurch erhält das Anschauungsobjekt die Form eines kleinen Bildes." ${ }^{62}$ Das Pendant zur Isolation klar umrissener Wahrnehmungsfelder, deren Abbildung strikt nach den 'Wahrheit' verbürgenden Gesetzen der Perspektive zu erfolgen hat, ist die Struktur der Bilderkette. Schritt für Schritt tastet sich das Auge von Objekt zu Objekt und setzt das Ganze nach Art eines Mosaiks additiv aus seinen Einzelteilen zusammen. ${ }^{63}$

Rahmenschau und Bilderkette sind freilich nicht nur Idealformen der Wahrnehmung bzw. Schulungsinstrumente für deren Reglementierung, sie bestimmen nahezu durchgängig auch den Geschmack der Zeit. Das wird nicht zuletzt im Bereich der Landschaft deutlich. ${ }^{64}$ Die Vorliebe etwa für Durchblicke, für die Begrenzung von Fernsichten durch einen rahmenden Vordergrund prägt die Natur nicht allein dort, wo sie wie in der Gartenkunst vom Menschen gestaltet oder wie in der Landschaftsmalerei künstlerisch 'nachgeahmt' wird. Selbst die zufällig begegnende Natur wird ihr nach Kräften unterworfen, beispielsweise durch die Wahl eines entsprechenden Betrachterstandpunkts. Kleist selbst liefert treffende Beispiele dieser Vorliebe. Kaum eine Landschaft, die er der Beschreibung für würdig hält, findet sich in seinen Briefen, die nicht dem Prinzip der Rahmenschau gehorchte und sich dadurch selbst gleichsam als ein malerisches Arrangement präsentierte. "Wir sahen von einem hohen Berge herab, rechts und links dunkle Tannen, ganz wie ein gewählter Vordergrund; zwischen durch eine Gegend, ganz wie ein geschlossenes Gemälde." ${ }^{65}$ Aus dieser Geschmackslage und ästhetischen Erwartungshaltung erklärt sich wenigstens teilweise die Irritation Kleists durch eine Naturdarstellung, der mit dem rahmenden Vordergrund genau das fehlt, was die äußere Natur selbst allererst zum "geschlossenen Gemälde" und damit goutierbar macht.

Neben dem bildimmanenten Rahmen scheint Kleist überdies die Möglichkeit zu vermissen, den Mönch am Meer nach dem Prinzip der Bilderkette optisch zu erschließen; "zwei oder drei... Gegenstände" jedenfalls ergeben noch lange keine Kette, an der sich das Auge entlangtasten könnte. Und tatsächlich ist damit ein wichtiger Aspekt bezeichnet, durch den sich der Mönch am Meer von der Tradition der Landschaftsmalerei unterscheidet. Dort - also etwa bei den Niederländern, bei Lorrain, Poussin und ihren Nachfolgern - ist der Raum durch die Zentralperspektive geordnet, meßbar und begehbar. Räumlich hintereinander gestaffelte, perspektivisch sich verkleinernde Gegenstände bieten dem Auge Halt und lenken es Schritt für Schritt in die Ferne. Distanzen können so abgeschätzt werden, der Raum wird plastisch, seine Tiefe kommensurabel, und der Betrachter vermag sich zu orientieren. All dies vermeidet Friedrich im Mönch am Meer. Auf einen eindeutig bestimmbaren Betrachterstandpunkt und die Zentralperspektive verzichtet er ebenso wie auf "Gegenstände," die als räumlich geschichtete Glieder einer optischen Kette einen "perspektivischen Pfad"66 in die Weite des Raums legen könnten. Einziger möglicher Vergleichsmaßstab ist die Figur des Mönchs im Mittelgrund nur gibt es eben nichts zu vergleichen. Der Raum, dargestellt durch übereinander angeordnete Farbstreifen, wird nun in der Tat unermeßlich, und dieser Eindruck wird dadurch verstärkt, 
daß kein bildimmenenter Rahmen seinem Drängen über die Bildränder hinaus, auf die die Farbstreifen abrupt prallen, Einhalt gebietet. Der Betrachter des Bildes aber verliert alle Orientierung. ${ }^{67}$

Spätestens jetzt wird deutlich, daß der von Kleist eingeklagte Vordergrund sowie das Prinzip der Rahmenschau überhaupt allein mit Hinweis auf die rational-didaktische und die ästhetische Funktion nicht angemessen zu begreifen sind. ${ }^{68}$ Durch das ganze 18. Jahrhundert hindurch gehört die unermeßliche Weite des Meers zu jenem Bereich der Natur, der als "erhaben" klassifiziert wird. ${ }^{69}$ Dieser Begriff enthält bekanntlich in aller Regel die Theorie eines ganz bestimmten Modus der Wahrnehmung und ihrer emotionalen Verarbeitung. Erhaben ist die Natur nur dort, wo sich der Mensch ihr unterlegen fühlt. Anders aber als bei gewaltsamen, eruptiven Naturereignissen ist das Subjekt der ungeheuren Weite nicht physisch, sondern kognitiv unterlegen: Der grenzenlose Raum, der die Idee des Unendlichen assoziieren läßt, stürzt auf es ein, überfordert seine Auffassungsfähigkeit und setzt es in Verwirrung und Desorientierung. Es ist dies eine Folge der langwierigen Durchsetzung der frühneuzeitlichen astronomischen Theorien, die die alte Ordnung des Kosmos umwälzten, den kosmischen Raum ins Immense, ja Unendliche explodieren ließen und damit die Raumwahrnehmung überhaupt revolutionierten. Doch die Theorien des Erhabenen berichten nicht nur von tiefer Unlust, sondern auch von deren Umschlagen in Lust, das sich einem Aufschwung, einer Erhebung des Subjekts verdankt, die das Gefühl der Bedrohung und Unterlegenheit aufhebt. Ähnlich wie die Sehnsucht und doch ganz anders ist das Erhabenheitsgefühl zusammengesetzt aus einem Abbruch, den die Natur tut, und einem Anspruch, den das Subjekt macht. Vieles spricht dafür, die Theorien des Erhabenen nicht lediglich als Beschreibungen eines ambivalenten Gefühls angesichts der übermächtigen Natur zu lesen, sondern als strategische Konzepte, die einen bestimmten Punkt im Prozeß der Selbstbehauptung und Selbstermächtigung des neuzeitlichen Subjekts markieren, das selbst dort, wo es der Natur nicht gewachsen ist, versucht, sie wenigstens subjektiv zu entmächtigen. Es braucht hier nicht im einzelnen zu interessieren, wie die Erhebung, die dies leistet, sich vollzieht, ob als Aktivierung aller Seelenkräfte, die zur kognitiven Annäherung an das unfaßbar scheinende Objekt führt, oder, wie Kant und Schiller darlegen, im Vorgang einer Selbstbewußtwerdung der Vernunft als eines "übersinnlichen Vermögens," das die "Überlegenheit" des Subjekts "über die Natur selbst in ihrer Unermeßlichkeit" begründet. ${ }^{70}$

Wichtig für das Verständnis der Kleistschen Metapher ist hingegen, daß die Erhebung unter einer Bedingung steht: der Bedingung der Sicherheit des Subjekts. Dies scheint zunächst nur die, mit Kant zu reden, "dynamisch-erhabenen," gewaltsamen Naturerscheinungen zu betreffen. Ihnen gegenüber, die wirkliche Gefahr bedeuten können, muß sich das Subjekt in Sicherheit wissen, da es andernfalls von bloßer Furcht befallen wird, die die Möglichkeit der Erhebung vereitelt. Dieser Vorbehalt gilt jedoch ebenso für die "mathematisch-erhabene," unermeßliche Natur. Denn auch diese kann so vehement auf das Subjekt eindringen, daß es ihr nicht standzuhalten vermag. Immer wieder wird im Zusammenhang mit dem Erhabenen festgestellt, daß der Ausblick ins Unermeßliche einen Schwindel bewirke, der das Subjekt zwinge, die Augen zu schließen. Das Subjekt reagiert auf den Ansturm des optischen Reizes, den es nicht bewältigen kann, indem es den Betrieb der Wahrnehmung einstellt und sich hinter seinen geschlossenen Augenlidern in Sicherheit bringt. So schreibt etwa Albrecht von Haller, die Umschau von einem Berg aus schildernd:

Durch den zerfahrnen Dunst von einer dünnen Wolke

Eröffnet sich zugleich der Schauplatz einer Welt,

Ein weiter Aufenthalt von mehr als einem Volke

Zeigt alles auf einmal, was sein Bezirk enthält;

Ein sanfter Schwindel schließt die allzu schwachen Augen, 
Die den zu breiten Kreis nicht durchzustrahlen taugen. ${ }^{71}$

Und auch Moses Mendelssohn bemerkt:

Die Sinne, die etwas zusammengehörendes warnehmen, schweifen umher, die Grenzen desselben zu umfassen, und verlieren sich ins Unermeßliche. Daraus entstehet... Anfangs ein Schauern, das uns überläuft, und sodann etwas dem Schwindel ähnliches, das uns nöthiget, die Augen von dem Gegenstande abzuwenden. Das große Weltmeer... (und andere Gegenstände - CB.) erregen diese Art von Empfindung.. . ${ }^{72}$

Das Schließen des Auges ist nicht die einzige Möglichkeit, auf den überwältigenden und dennoch faszinierenden Eindruck zu reagieren. Wo er als ganzer nicht auszuhalten ist, liegt es nahe, ihn im Sinne der Rahmenschau zu beschneiden. ${ }^{73}$ Es sei gewiß, schreibt Christian Garve,

daß der Reiz dieser Ferne größer wird, wenn große majestätische, oder auch anmuthige Gegenstände, in der Nähe, unsern Blick an sich ziehn, und wir die Ferne, nur von einer Seite, gleichsam durch ein geöffnetes Thor erblicken. ${ }^{74}$

Eine solche Rahmung leistet zweierlei. Zum einen begrenzt sie das Unermeßliche auf einen gerade noch erträglichen Ausschnitt, birgt allerdings ebenso wie das Schließen der Augen die Gefahr, dadurch genau den erhabenen Charakter der Ferne zu zerstören. Zum anderen wird dem Betrachter ein Standort vor dem Rahmen angewiesen: Zwischen ihm und dem Unermeßlichen befinden sich "Gegenstände," die den "Blick an sich ziehn," damit das aktuelle optische Monopol der Ferne brechen und sich ihrer machtvollen Wirkung entgegenstellen. Das Subjekt kann sich der Weite aussetzen, sobald sie ihm aber bedrohlich wird, jederzeit seinen Blick hinter die Barriere zurückziehen und dort Halt finden. Dem schwindelerregenden Abgrund des Raums ${ }^{75}$ gegenüber bewirkt damit die Rahmenschau - und schon der auf einen Vordergrund reduzierte Rahmen, der den Vorteil hat, die Erhabenheit des Ausblicks nicht zu sehr zu beeinträchtigen - genau das, was Rousseau an einem Geländer rühmt, das den Betrachter der Natur von einer tiefen Gebirgsschlucht trennt: ${ }^{76}$ Rahmenschau und Vordergrund stiften Sicherheit. Man wird dies zu den rein ästhetischen Erfordernissen hinzudenken müssen, wenn man sich Klarheit darüber verschaffen will, was jene vielgestaltigen optischen 'Geländer' eigentlich leisten, ohne die kaum ein Landschaftsgemälde des 17. und 18. Jahrhunderts den Ausblick in die Ferne darstellt, jene Terrassen, bewachsenen Anhöhen, umgestürzten Säulen und gruppierten Staffagefiguren.

In diesen Zusammenhängen nun erschließt sich Kleists Metapher. Wo Rahmenschau und Vordergrund entfallen, die die Ansicht des Unermeßlichen begrenzen, so den Betrachter sichern und stabilisieren und damit, psychologisch gesehen, dieselbe Funktion erfüllen wie das Schließen der Augen, da entgrenzt sich der Raum und überwältigt das Subjekt. In genau dieser Situation befände sich ein Mensch, dem die Augenlider weggeschnitten wären. Die natürliche Einschränkung seines Blickfelds wäre beseitigt, und das Auge, das nicht mehr geschlossen werden könnte, stünde dem anflutenden Reiz des unbegrenzten Raumes schutzlos offen. Die Metapher von den weggeschnittenen Augenlidern ist kein 'neutrales,' einen Sachverhalt nüchtern und distanziert beschreibendes Bild, sondern scheint im höchsten Grade affektiv aufgeladen. Von blutiger Verletzung ist die Rede, von einem unerhörten Eingriff in die Autonomie des Leibes und der Person - bewirkt vom ungehemmten Andringen des Raumes. Steht also am Ende hinter der emotionalen Wucht der Metapher die Enttäuschung jenes Anspruchs des neuzeitlichen Subjekts auf Ermächtigung und Erhebung über die Natur, den die Theorien des Erhabenen fortgeschrieben hatten, eines Anspruchs, der hier zu Boden geschlagen wird, weil die Bedingungen seiner Erfüllung verweigert werden? ${ }^{77}$

Verantwortlich aber ist ein Gemälde, ein bloßes Bild. Es beweist die große Sensibilität ei- 
ner heute längst abgeschliffenen Wahrnehmung des unermeßlichen Raumes, daß schon dessen ungemilderte Abbildung so tiefe Beunruhigung zu bewirken vermag. Das Abbild scheint dem Urbild an Wirkungsmacht kaum nachzustehen. Es liegt daher nahe, daß Kleist den Maler Friedrich auf einer "Bahn" erblickt, die letztlich zu einer besonderen Art des 'Realismus' führt, zu einer Aufhebung der Differenz von Urbild und Abbild. Dazu fehlt lediglich, daß Friedrich seine Landschaften "mit ihrer eignen Kreide und mit ihrem eigenen Wasser mahlte," mit den Materialien also, aus denen sie in natura zusammengesetzt sind. Dann gäbe es keinen Unterschied mehr von Bild und Natur, selbst die Füchse und Wölfe würden sich täuschen lassen und vor dem Bild zu heulen beginnen wie vor der Natur selbst. ${ }^{78}$ Kleist stellt somit am Mönch am Meer die gleiche wirkungsästhetische Tendenz fest, die Friedrich Wilhelm Basilius von Ramdohr dem "Tetschener Altar" zum Vorwurf gemacht hatte. Friedrich, so Ramdohr, erwecke keine "ästhetische," sondern eine "pathologische Rührung," denn er ziele "auf die Erregung eines affektvollen Zustandes in dem Beschauer, wie er ihn etwa vor den dargestellten Sujets in der Natur selbst erhalten würde." ${ }^{79}$

IV.

Der Eindruck einer im genannten Sinn 'realistischen' "Bahn" Friedrichs gehört zu jenen Details im Text, deren Summation es erlaubt, Kleists Wahrnehmung der Raumdarstellung im Mönch am Meer noch weiter zu präzisieren. "Einförmigkeit und Uferlosigkeit," der Verzicht auf eine den Raum begehbar und meßbar machende perspektivische Gegenstandskette und schließlich das Fehlen eines Vordergrundes, der die erhabene Unermeßlichkeit eingrenzen und ihren Andrang abdämmen könnte: Das sind die hauptsächlichen Charakteristika des Bildraums, die Kleist irritiert aufführt. Er weist damit, wie schon gesagt, auf einen Bruch Friedrichs mit der Tradition hin, einen Bruch, der zwar radikal ist, jedoch in der Kunst um 1800 durchaus Vergleichbares hat. Wolfgang Schöne hat in seiner Untersuchung des Lichts in der Malerei gezeigt, daß der Begriff eines unbegrenzten Raums kunstgeschichtlich erst für die Zeit der Wende zum 19. Jahrhundert sinnvoll ist.

Landschaftsbilder um 1800 zeigen ..., wenn man sie mit Landschaftsbildern des 17. und 18. Jahrhunderts vergleicht, deutlich, daß die Grenzen des bisherigen Naturraumes mit einem Schlage gefallen sind, ein Vorgang, der vielleicht im Bilde einer eruptiven (wenn auch lautlosen) Entgrenzung des begrenzten Naturraumes in den unbegrenzten kosmischen Raum beschrieben werden kann. ${ }^{80}$

Kleists Bildbesprechung geht allerdings über die Feststellung dieser Neuerung noch einen Schritt hinaus, oder genauer: Sie erkennt im Mönch am Meer Ansätze zu deren extremster Ausprägung. Es mutet zunächst wohl übertrieben an, wollte man die Metapher von den weggeschnittenen Augenlidern so verstehen, als sei in ihr nicht nur eine relative Entgrenzung, eine Erweiterung des Blickfelds (um den von den Lidern normalerweise verdeckten Bereich) ausgedrückt, sondern gewissermaßen dessen absolute Entgrenzung auf einen Blickwinkel von $360^{\circ}$. Und doch scheint Kleist etwas in dieser Art zu meinen. Denn wie sonst ließe sich der Standpunkt des Betrachters eines Tafelbildes als "Mittelpunct" eines Kreises begreifen? Was Kleist hier offenbar andeuten will, ist eine Verwandtschaft des Mönchs am Meer mit den Rundpanoramen, die in dieser Zeit ihren Siegeszug durch Europas Städte antraten.

Die Kunstform des Rundpanoramas, eines der ersten Massenmedien, war zwischen 1785 und 1790 gleichzeitig von Robert Barker und Johann Adam Breysig erfunden und entwickelt worden, nachdem schon in den 1770er Jahren Panoramazeichnungen (als Vertikal- und Horizontalpanoramen) in den "Erdwissenschaften" Verwendung gefunden hatten. ${ }^{81}$ In der Tat war das Rundpanorama, wie die Zeitgenossen feststellten, ein "Gemälde ohne Grenzen." ${ }^{82}$ Es 
stellte, in einem meist eigens dafür errichteten Ausstellungsgebäude, einen $360^{\circ}$-Ausblick auf eine Stadt, Landschaft oder ein historisches Ereignis dar, wurde von oben beleuchtet und von einer abgedunkelten Plattform in der Mitte aus betrachtet. Diese Anlage erforderte die Preisgabe der Zentralperspektive zugunsten einer Polyperspektive. Kleist hat im August 1800 das in Berlin ausgestellte "berühmte Panorama der Stadt Rom" besichtigt und in einem Brief ausführlich beschrieben. Wilhelmine, die Braut, wird angehalten, sich das Panorama als "einen inwendig bemalten runden Turm" vorzustellen, doch hat diese Form, wie überhaupt die Ausführung, Kleists Beifall nicht gefunden. Auf das gewissermaßen hyperrealistische Telos des Panoramas hinweisend, schreibt er:

Denn da es nun doch einmal darauf ankommt, den Zuschauer ganz in den Wahn zu setzen, er sei in der offnen Natur, so daß er durch nichts an den Betrug erinnert wird, so müßten ganz andere Anstalten getroffen werden. Keine Form des Gebäudes kann nach meiner Einsicht diesen Zweck erfüllen, als allein die kugelrunde. Man müßte auf dem Gemälde selbst stehen, und nach allen Seiten zu keinen Punkt finden, der nicht Gemälde wäre. ${ }^{83}$

Nicht nur zwischen Kleist, auch zwischen Friedrich und der Idee des Panoramas lassen sich Verbindungslinien rekonstruieren. Friedrich nämlich dürfte Panoramen nicht nur ebenfalls aus eigener Anschauung gekannt haben, ${ }^{84}$ es scheint überdies, als habe er sich um 1810 selbst mit dem Plan eines Riesengebirgspanoramas getragen. ${ }^{85}$ Bedeutsamer sind freilich die Indizien einer 'panoramatischen' Intention, die sich in Friedrichs kunsttheoretischen Äußerungen und vor allem in seinen Gemälden finden. Gerhard Eimer hat den Versuch unternommen, einen Einfluß des schwedischen Schriftstellers Thomas Thorild, der seit 1795 als Professor für Literatur und Ästhetik in Greifswald wirkte, auf Caspar David Friedrichs kunsttheoretische Ansichten nachzuweisen. ${ }^{86}$ Von Thorild stammt eine Aussage, die an Kleists Beschreibung des Gemäldebetrachters als "Mittelpunct im ... Kreis" denken läßt: "Ein Auge im Mittelpunkt der Welt, das die Unendlichkeit umfaßt, das allein würde richtig sehen, würde das Ewige sehen, die wahre Harmonie." ${ }^{87}$ Der wahrhaft göttliche "Allblick" als Ideal der 'richtigen' Wahrnehmung wäre nach Thorild also nichts anderes als eine unendlich verfeinerte Panoramaschau. Es ist daher nicht weiter verwunderlich, daß das Bild, in das er gefaßt wird, bei den Verfertigern von Panoramen wiederkehrt, wenn auch in pragmatischer Wendung und mit weit weniger outriertem Anspruch. Horace Benedict de Saussure etwa, der berühmte Alpenforscher, von dem das erste Horizontalpanorama stammt (1776), hat die Schwierigkeiten bei dessen Aufnahme ausführlich geschildert:

Es bedarf beim Zeichner einer einzigartigen Anstrengung an Aufmerksamkeit und einer schwierigen Anwendung der Gesetze der Perspektive, um auf vertikale Flächen und gerade Linien Dinge zu projezieren, die er in Wahrheit innerhalb einer Linie sieht, die ihn umgibt und auf konzentrischen Kreisen, deren Mittelpunkt sein Auge ist. ${ }^{88}$

Der Frage nach einem Zusammenhang zwischen der Idee göttlicher Allschau und dem Panorama kann hier nicht nachgegangen werden. Ihre Brisanz zeigt sich, soviel sei jedoch erwähnt, besonders eindringlich an Jeremy Benthams Entwürfen eines Panopticon (1787ff.), jener monströsen Vision eines kreisrunden, nach Art des Panoramas um ein beobachtendes Auge herumkonstruierten Gefängnisses, das die perfekte optische Kontrolle der Insassen gewährleisten und damit eine Macht ausüben sollte, die allein vom Blick ausging. ${ }^{89}$

Caspar David Friedrich nachzusagen, er habe Thorilds Ideal der richtigen Wahrnehmung durch ein Auge im Mittelpunkt in die künstlerische Praxis umsetzen wollen, wäre sicherlich weit überzogen. Was sich allerdings mit Grund vermuten läßt, ist seine Absicht, bestimmte 'Fehler' der Landschaftsmalerei anhand dieses Ideals zu korrigieren.

Denn was die neueren Landschaftsmaler in der Natur in einem Kreis von 100 Graden gesehen, pressen sie unbarmherzig in den Sehwinkel von 45 Graden zusammen. Und was also in der Na- 
tur durch große Zwischenräume getrennt lag, berührt sich hier im gedrängten Raume, überfüllt und übersättigt das Auge und macht auf den Beschauer einen widrigen beängstigenden Eindruck. Und das Element des Wassers zieht immer den kürzeren dabei, und das Meer wird zur Pfütze. $^{90}$

Friedrichs Kritik scheint sich nicht nur an dem verfälschenden Zusammendrängen der Gegenstände im Bild zu entzünden, sondern auch an dem in der Landschaftsmalerei durchaus üblichen "Sehwinkel" selbst. Seinerseits geht Friedrich hier andere Wege. Der Blickwinkel vieler seiner Gemälde wirkt überdehnt, und eine dementsprechende Kompositionsweise, von Willi Wolfradt als "hyperbolisches Schema" bezeichnet, verstärkt den Eindruck, als seien die Landschaften mit einem Weitwinkelobjektiv aufgenommen oder in einem Hohlspiegel eingefangen: Die Horizontgerade ist "wie die Koordinate zwischen zwei Hyperbelkurven gezogen," die einander spiegelbildlich entsprechen. Viele Bilder Friedrichs weisen dieses Schema auf; neben dem Mondaufgang am Meer, an dem Wolfradt es entwickelt hat, ${ }^{91}$ wird es vielleicht am radikalsten im "Großen Gehege" (Abb. 3) durchgeführt, aber auch im Mönch am Meer zeigt es sich ansatzweise: ${ }^{22}$ Die Umrißlinie der Düne biegt sich nach oben, die des Wolkenbandes nach unten. Tendenziell entsteht so auch beim Mönch am Meer ein Raum, wie man ihn in einem Hohlspiegel sehen könnte, ein Raum, der sich vor dem Betrachter leicht zu wölben, ihn zu umgeben scheint. Der Bildraum neigt dazu, sich zu totalisieren. Unterstützt wird diese Wirkung durch das große Bildformat $(110 \times 171,5 \mathrm{~cm})$, vor allem jedoch durch das von keinem bildimmanenten Rahmen gebremste Drängen des Horizonts über die Bildränder hinaus - ein Phänomen, das schon vor den vor der Natur verfertigten Veduten des 18. Jahrhunderts her bekannt ist, in denen das Sinngefüge der "idealen Landschaft" preisgegeben war und mit ihm die Sogwirkung ins Innere des Bildes. ${ }^{93}$

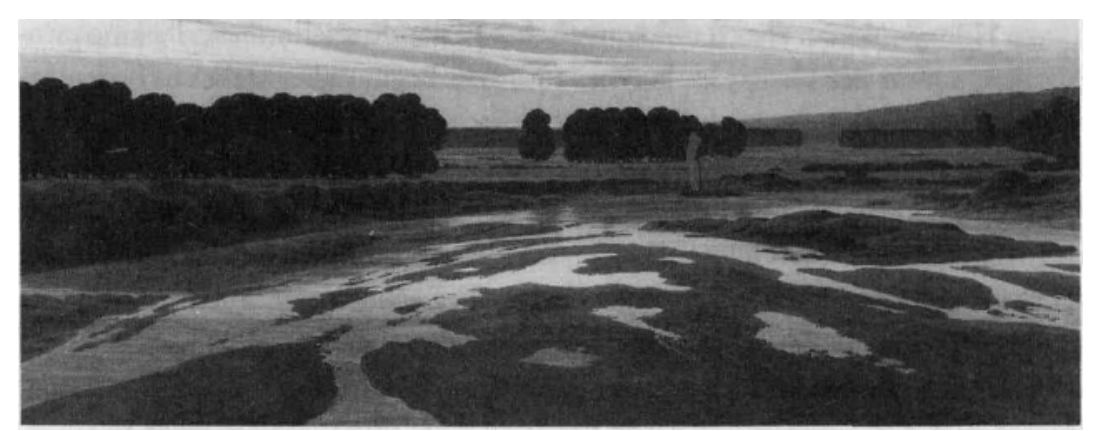

Abb. 3: Caspar David Friedrich, Das große Gehege

Diese quasi panoramatischen Züge des Gemäldes begründen Kleists Gefühl, als stünde er vor dem Mönch am Meer mit lidlosen, unbegrenzten Augen im Zentrum eines Kreises. Daß er die Wirkung des gemalten Raumes, der durch keinen haltgebenden Vordergrund beschränkt ist, nur in einem Bild der Gewalt begreifen kann, erlaubt es dabei, in Kleists Position den Vorbehalt der Erhabenheitstheoretiker zu erkennen, für die das potentiell Erhabene so lange bloß bedrohlich ist, wie ihm das Subjekt ungeschützt gegenübersteht. Damit ist freilich nicht zwingend eine negative Bewertung des Gemäldes verbunden, das diese Wirkung hervorruft. Immerhin ist es ja möglich, an der Metapher der weggeschnittenen Augenlider eine weitere, im bisherigen Gang der Untersuchung vernachlässigte Bedeutungsschicht zu aktualisieren. Läßt schon die wahrhaft exorbitante Bildfindung als solche auf eine tiefe Faszination des Autors schließen, so kann die Metapher auch inhaltlich in diesem Sinne gedeutet werden: als Verbildlichung der Unmöglichkeit wegzusehen, des hypnotischen Gefesseltseins, der geradezu 'traumatophilen' Bannung durch das 'Traurige,' 'Unbehagliche,' Todesnahe, Bedrohliche und Gewalttätige des Gemäldes. Diese Lesart hätte das literarische Werk Kleists auf ihrer Seite, 
wird jedoch vom Text der Abendblätter sogleich wieder in Frage gestellt. Zwar heben die nächsten Sätze, die nach dem jähen Höhepunkt ein eher feuilletonistisches Parlando anstimmen, die innovatorische Qualität des Gemäldes hervor, an ihrem Beginn aber steht ein bedeutsames "gleichwohl," das eine Spannung aufbaut zwischen dem etwas schulterklopfenden Lob und jener Metapher: "Gleichwohl hat der Mahler Zweifels ohne eine ganz neue Bahn im Felde seiner Kunst gebrochen ...." Und lange ließe sich zudem darüber rechten, ob nicht mit diesem und dem folgenden Satz der Ton ins Ironische gleitet, ${ }^{94}$ in eine Ironie, die, ebenso wie auch im Fall der Besuchergespräche Brentanos, nicht zuletzt die unterschwellige Funktion haben könnte, sich von einem zutiefst Verstörenden und Bedrohlichen zu distanzieren. Alles hängt dabei von der Färbung der "wahrhaft Ossiansche[n] oder Kosegartensche[n] Wirkung" ab, die dem fiktiven Krähengemälde zugesprochen wird. Welche Bewertung sich in dieser, heute eher süffisant anmutenden Wendung verbirgt, dürfte sich allerdings kaum mehr befriedigend rekonstruieren lassen. ${ }^{95}$

Kleists Irritation beruht auf der Verletzung eines Konzepts, dessen Zeit im Ablaufen ist. Kants Kritik der Urteilskraft und Schillers Aufsätze aus den 90er Jahren sind die letzten Höhepunkte der Erhabenheitsdebatte, denen nur noch wenig Bedeutendes folgt. Es ist wohl kein Zufall, daß das Panorama in denselben Jahren seinen Aufstieg beginnt, in denen das Erhabene niedergeht - obgleich nicht endgültig, zeigt es sich als Phänomen doch auch im 19. Jahrhundert noch verschiedentlich in dieser oder jener Form. Grundsätzlich scheint das Panorama eine höhere Adaptation der Wahrnehmung an den Anblick der Weite vorauszusetzen. Ironischerweise wird das gerade durch jene, offenbar nicht seltenen Besucher belegt, die seinem Eindruck nicht gewachsen waren und von Schwindel, Seekrankheit und Ohnmacht ergriffen wurden, ${ }^{96}$ denselben Symptomen also, die man aus den Erhabenheitstheorien als Reaktion auf und Schutz vor Reizüberflutung kennt. Aufs Ganze gesehen aber liegt dem Erfolg des Panoramas als Massenmedium eine höhere Fähigkeit der Subjekte zugrunde, das Unermeßliche zu ertragen, als auf der wahrnehmungsgeschichtlich früheren Stufe der Erhabenheitserfahrung. Und das ist nicht zuletzt gerade deren Erfolg. Immer wieder ist ja die Erfahrung des Erhabenen im 18. Jahrhundert als ein Akt der Gewöhnung und Schulung beschrieben worden, der sich anfangs nur in einem umhegten Bereich der Sicherheit vollziehen kann, es dem Subjekt aber schließlich erlauben sollte, dem Erhabenen auch ungeschützt gegenüberzutreten einem Erhabenen freilich, das im selben Moment aufhört, erhaben zu sein, und damit allmählich immer gewöhnlicher und gleichgültiger wird. Dieser Punkt ist, wie man weiß, inzwischen längst erreicht. Er hat sich jedoch schon im 18. Jahrhundert angekündigt, und zwar insbesondere in jenen zahlreichen Theorien, die die "Erhebung" als einen Prozeß der Steigerung aller kognitiven Kräfte des Subjekts begreifen, dem es schließlich gelingt, das zunächst unfaßbar Scheinende nun doch annähernd zu erfassen. ${ }^{97}$

An Goethe läßt sich dieser Vorgang, der ein zugleich individueller und historischer Gewöhnungsprozeß ist, gut beobachten. Er, der sich schon in Straßburg Höhenschwindel und "Seh-Krankheit" (Oettermann) mit rigorosen Abhärtungskuren ausgetrieben hatte, ${ }^{98}$ schreibt von seiner zweiten Schweizer Reise über das Erhabene:

Ich möchte aber sagen wenn wir einen solchen [erhabenen] Gegenstand zum erstenmal erbliken so weitet sich die ungewohnte Seele erst aus und es macht dies ein schmerzlich Vergnügen eine Überfülle die die Seele bewegt und uns wollüstige Thränen ablokt, durch diese Operation wird die Seele in sich grösser ohne es zu wissen und ist iener ersten Empfindung nicht mehr fähig, der Mensch glaubt verlohren zu haben, er hat aber gewonnen, was er an Wollust verliert gewinnt er an innrem Wachsthum .... ${ }^{99}$

In der Folge muß der Eindruck des Unermeßlichen mit einiger Mühe revitalisiert werden, um noch ein emotionales Surplus abzuwerfen. Um nicht das Gipfelerlebnis vorzeitig abzuschwä- 
chen, vermeiden es daher die Wanderer bei einer Besteigung des Dole-Gipfels "sorgfältig... uns nach der Gegend umzusehen, um derent willen wir eigentlich herauf stiegen." ${ }^{100}$ Einer vergleichbaren Technik bedient sich Albano in Jean Pauls Titan, der den Aussichtspunkt mit verbundenen Augen betritt, um den Eindruck der Landschaft durch die plötzliche Enthüllung zu steigern. ${ }^{101} \mathrm{Daß}$ bei diesem Stand der Wahrnehmung auch angesichts des Mönchs am Meer, den Goethe am 18. 9. 1810 in Friedrichs Atelier sah, keine Rede von "iener ersten Empfindung" ist, scheint nur plausibel. Ohne alle Zeichen von Irritation vermerkt Goethes Tagebuch lapidar: "Zu Friedrich. Dessen wunderbare Landschaften. Ein Nebelkirchhof, ein offnes Meer." 102

Wie Goethes und Albanos Verfahren der Effektverstärkung setzt auch das Panorama einen gewissen Grad der Erosion erhabener Eindrücke voraus. Umgekehrt aber treibt es diese weiter voran, indem es, wie Günter Hess und Stephan Oettermann übereinstimmend festgestellt haben, zum "Muster" wird, "nach dem sich von nun an Seherfahrungen organisieren," zur "Schule des Blicks,... in der der extreme Sinneseindruck, das sensationelle, weil ungewohnte Erlebnis immer wieder und wieder geübt werden konnte, bis es zur Selbstverständlichkeit und zum alltäglichen Bestandteil menschlichen Sehens wurde." ${ }^{103}$ In dieser Hinsicht ist der panoramatische Blick in der Tat vereinnahmender Zugriff auf das Unermeßliche und als solcher ebenso wie das Erhabene, das er tendenziell hinter sich läßt, eine Form der kognitiven Aneignung und Beherrschung der Natur.

So zutreffend diese Feststellung insgesamt ist, so wenig wird man, ausschließlich von ihr geleitet, der Frühzeit des panoramatischen Blicks gerecht, in der Brentanos und Kleists Text angesiedelt ist. In ihr gibt es einen weiteren Kontext, der die Attraktion der Panoramaschau begründet. Es ist derselbe, aus dem heraus Brentano gegen den Mönch am Meer argumentiert.

Panoramablicke finden sich in vielen romantischen Texten, deren Held sehnsüchtig in die Ferne zieht, und sind dort nicht selten die Erscheinungsweise dieser Ferne. Bei Eichendorff heißt es einmal:

Der Garten selbst stand auf einer Reihe von Hügeln, wie eine frische Blumenkrone über der frischen Gegend. Von jedem Punkte desselben hatte man die erheiternde Aussicht in das Land, das wie in einem Panorama ringsherum ausgebreitet lag. ${ }^{104}$

Der panoramatische Ausblick in die Weite fällt weder unter die Kategorie des Erhabenen, noch wird er in irgendeiner Weise als unbehaglich empfunden: Er ist vielmehr "erheiternd" und verheißungsvoll und offenbar von ganz anderen subjektiven Befindlichkeiten bestimmt als vergleichbare Erfahrungen im Umkreis der Erhabenheitskonzeption. In diesem Zusammenhang nun taucht ein Bild auf, das geradezu als das positive Pendant zu Kleists Metapher der weggeschnittenen Augenlider gelten kann.

Wer Studenten auf ihren Wanderungen sah, wie sie frühmorgens aus dem dunkeln Tore ausziehen und den Hut schwenken in der frischen Luft, wie sie wohlgemut und ohne Sorgen über die grüne Erde reisen, und die unbegrenzten Augen an blauem Himmel, Wald und Fels sich noch erquicken, der mag gern unsern Grafen auf seinem Zuge durch das Gebirge begleiten. ${ }^{105}$

Mit dem "dunkeln Tore" lassen die Studenten die Enge und Düsternis der Normalität hinter sich und geben sich dem Sog der Ferne hin. Wenn von ihren "unbegrenzten Augen" die Rede ist, so scheinen nur metonymisch ihre Blicke gemeint, die in die durch nichts verstellte Ferne schweifen, ins Grenzenlose gehen. Das entspricht ganz einer panoramatischen Wahrnehmung der Natur. Aber Eichendorff sagt nicht "Blicke," sondern "Augen," wünscht also offensichtlich die Bedeutung "Sehorgan" festzuhalten. Dadurch erst wird das Bild frappant: Die "unbegrenzten Augen" werden geradezu mit dem Kosmos identisch; Sehendes und Gesehenes, Subjekt und Objekt fallen in eins. Eichendorffs Bild bringt die Sehnsucht des in die Weite schweifenden Blicks in engste Verbindung mit Vorstellungen von Entgrenzung und Einheit 
- eine, wie oben skizziert, durchaus zeittypische Konstellation. Ist die Ferne das, was die Sehnsucht auslöst, so ist sie, nach Eichendorffs Bild, im Akt der Sehnsucht selbst auch schon erreicht. Der sehnsüchtige Blick wird zum unbegrenzten Auge, in dem die Trennung von Ich und Welt aufgehoben und die Ferne immer schon enthalten ist. Sehnsucht erscheint so als ihre eigene Erfüllung; erneut erweist sich ihre Selbstreferenzialität.

Auch Kleists lidlose Augen sind "unbegrenzte Augen" und doch gänzlich von denen Eichendorffs unterschieden. In Eichendorffs Bild gibt sich das sehnsüchtige Subjekt lustvoll der Ferne preis, entgrenzt sich und wird mit der panoramatisch es umgebenden Natur eins. Das Panorama ist in diesem Kontext nicht Medium der optischen Unterwerfung des Unermeßlichen, sondern Verlockung für das Ich, sich von einem Zentrum aus ins Unbegrenzte zu erweitern und sich mit ihm zu vereinigen. Bei Kleist hingegen wird die panoramatische Weite tendenziell als Bedrohung gefaßt, die die Souveränität des Ichs verletzt und nach dem Vorbild der Erhabenheitstheorien durch einen Schutzwall eingedämmt werden muß. Daß solche Bedrohung in der Sehnsuchtskonzeption zwar keineswegs verschwunden, wohl aber von Euphorie verdeckt ist und daß dementsprechend Brentanos Probleme mit dem Mönch am Meer völlig anderer Natur sind als diejenigen Kleists, ${ }^{106}$ hängt mit den jeweils zugrunde liegenden Begriffen vom Subjekt zusammen. Dem auf Selbsterhaltung und Herrschaft bedachten bürgerlichen Subjekt der Erhabenheitstheorien, das seine Unterlegenheit gegenüber der Natur ummünzen will in Erhebung über diese, steht in den romantischen Sehnsuchtskonzeptionen ein Subjekt gegenüber, das mit der Auflösung seiner Individualität liebäugelt. Ist es insofern antibürgerlich, so bleibt es doch zugleich dialektisch auf das bürgerliche Charaktermodell bezogen. Denn der Wunsch nach 'dionysischer' Entgrenzung ist in dieser historischen Situation nicht zuletzt Reaktion auf jene fortschreitende zivilisatorische Verpanzerung des Ichs, die in den Theorien des Erhabenen ihren 'sublimsten' Ausdruck findet. Und so sehr auf der phänotypischen Differenz von Erhabenheit und Sehnsucht, Verhärtung und Auflösung, Ermächtigung und Entäußerung insistiert werden muß, bleibt doch festzuhalten, daß der sehnsüchtige Romantiker auch noch in anderer Hinsicht der bürgerlichen Welt zugehörig ist: Die Sehnsucht, sich in die Natur hinein zu entgrenzen und mit ihr einszuwerden, ist nicht allein als Wunsch nach Selbstaufgabe zu begreifen, sondern ebenso als narzißtische Größenphantasie, in der sich das Ich die Welt einverleibt. Unterschwellig ist auch sie eine Form der, obgleich phantastischen Aneignung von Natur.

Caspar David Friedrich hat, so scheint es, beiden Parteien nicht Genüge tun können. Seine Kunst fällt durch die Raster der konventionalisierten Erwartungshaltungen.

1 Zuerst erschienen in DVjs 64 (1990), 54-95. Für viele Gespräche, Anregungen und Korrekturen, ohne die diese Untersuchung anders aussähe, möchte ich Albrecht Koschorke in München danken. Für Kopien und Hinweise bedanke ich mich beim Freien Deutschen Hochstift, Frankfurt.

2 Zeitung für die elegante Welt (1810), Sp. 1880, zit. n. Helmut Börsch-Supan und Karl Wilhelm Jähnig, Caspar David Friedrich: Gemälde, Druckgraphik und bildmäßige Zeichnungen (1973), S. 76.

3 Vgl. die bei Börsch-Supan/Jähnig (S. 76f.) abgedruckten Texte.

4 Berliner Abendblätter, hrsg. Heinrich von Kleist, Nachwort und Quellenregister Helmut Sembdner (reprograph. Nachdruck o.J.), S. 47f.

5 Reinhold Steig, Heinrich von Kleists Berliner Kämpfe (1901), S. 262-268. - Helmut Sembdner, Die Berliner Abendblätter Heinrich von Kleists, ihre Quellen und ihre Redaktion (1939), S. 180-184. - Seit der zweiten, vermehrten und revidierten Auflage (1961) der von Sembdner herausgegebenen Kleist-Ausgabe des HanserVerlages kann man sich über den philologischen Sachverhalt an gut zugänglicher Stelle informieren. 
6 Das von Brentano und Arnim gemeinsam geschriebene Manuskript befindet sich im Besitz des Freien Deutschen Hochstifts in Frankfurt. Über die Verfasserschaft schreibt Gerhard Kurz, "Vor einem Bild: Zu Clemens Brentanos 'Verschiedene Empfindungen vor einer Seelandschaft von Friedrich, worauf ein Kapuziner,"' JbFDH (1988), 128-140, hier 128: "Von Brentanos Hand ist der erste Teil. Er umfaßt rund vier Fünftel des Ganzen und endet mit dem frivolen Dialog zwischen der Dame und einem Führer. Mit 'Während der ganzen Zeit hatte ein glimpflicher langer Mann mit einigen Zeichen von Ungeduld zugehört ...' beginnt der zweite Teil in Achim von Arnims Handschrift. Der letzte Satz ('Diese Rede gefiel mir so wohl...') stammt wieder von Brentano. Diese Aufteilung deutet darauf hin, daß die jeweiligen Teile tatsächlich von den Schreibern formuliert wurden und nicht der eine diktiert, der andere aufgeschrieben hat." (Zu Autorschaft und Textgeschichte vgl. jetzt auch Roswitha Burwick, "Verschiedene Empfindungen vor Friedrichs Seelandschaft: Arnim, Brentano, Kleist," ZfdPh, 107, Sonderheft [1988], 33-44.) Die von Kleist übernommenen Teile stammen durchweg von Brentano und rechtfertigen die Verfassersigle "cb." in den Abendblättern. Vollständig publiziert wurde Brentanos und Arnims Vorlage unter dem Titel "Verschiedene Empfindungen vor einer Seelandschaft von Friedrich, worauf ein Kapuziner" erstmals am 28. 1. 1826 in der in Frankfurt erschienenen Zeitschrift Iris. Unterhaltungsblatt für Freunde des Schönen und Nützlichen mit der Verfassersigle "B. A." (Nr. 20, 77f.). Vgl. den Ausstellungskatalog des FDH Dichter der deutschen Romantik: Zeugnisse aus dem Besitz des freien Deutschen Hochstifts (1976), S. 62f.; dort S. 60f. ein faksimilierter Teil des Manuskripts. Auf die Publikation in der Iris geht die zunächst irritierende Jahresangabe 1826 des nächsten Textabdrucks zurück: Clemens Brentano's Gesammelte Schriften, hrsg. Christian Brentano, IV (1852), S. 424-429 (im folgenden abgekürzt mit GS). Diese Wiedergabe, die - bis auf zwei minimale Abweichungen - im Wortlaut mit dem Iris-Druck identisch ist, jedoch in Interpunktion, Orthographie und graphischer Anordnung der Dialoge deutlich variiert, hat man lange Zeit für den Erstdruck gehalten. - Wie Friedhelm Kemp in den Anmerkungen zu der Brentano-Ausgabe des Hanser-Verlags (2. Aufl. [1973], II, 1219) zu der Auffassung kommt, der Text beziehe sich auf "die 1931 im Münchener Glaspalast verbrannte 'Seelandschaft mit Kapuziner' von Caspar David Friedrich," bleibt rätselhaft. Bei dem Brand ist weder ein Gemälde dieses Titels zerstört worden, noch können die beiden im Glaspalast ausgestellten Seelandschaften ("Dame am Meeresstrand," "Abend am Ostseestrand") als Gegenstand von Brentanos und Arnims Text in Frage kommen. Vgl. Georg Jacob Wolf, Verlorene Meisterwerke deutscher Romantiker: Mit einer Einleitung und beschreibendem Katalog (1931), Nr. 21, S. 17 und Nr. 26, S. 18; Abb. auf Tafel XVI.

7 An Arnim, 14. 10. 1810, in Heinrich von Kleist, Sämtliche Werke und Briefe, hrsg. Helmut Sembdner, 8. Aufl. (1985), II, 839f.

\section{Berliner Abendblätter (Anm. 4), S. 78.}

9 Die Kleist-Forschung hat sich nur sporadisch mit dem Text befaßt. Wo man eine Interpretation erwarten würde, etwa in den neueren Untersuchungen zu den Abendblättern (Heinrich Aretz, Bodo Rollka) oder in Arbeiten, die sich mit Kleists Verhältnis zur bildenden Kunst beschäftigen, wird er meist gar nicht oder allenfalls beiläufig erwähnt; eine Ausnahme bildet hier lediglich H.M. Brown, "'Zwischen Erde und Himmel': Kleist and the Visual Arts, with Special Reference to Caspar David Friedrich," German Life and Letters, 31 (1977/78), 157-166, hier 159-164. Eine Analyse vermißt man überdies in einigen Untersuchungen, die den Text immerhin ansprechen und würdigen: Steig (Anm. 5), 262-268. - Helmut Rehder, Die Philosophie der unendlichen Landschaft: Ein Beitrag zur Geschichte der romantischen Weltanschauung (1932), S. 175f. Ähnliches gilt letztlich auch für Peter Gebhardts Aufsatz, dessen Titel ernstzunehmen ist: "Notizen zur Kunstanschauung Heinrich von Kleists," Euphorion, 77 (1983), 483-499, hier 486-488. Ausführlicher neuerdings: Roswitha Burwick (Anm. 6). Eine größere Untersuchung wird demnächst Andreas Ammer als Einleitung zu seiner noch ungedruckten Dissertation vorlegen: Horrorgraphie: Das Aufschreiben der Angst und die Schrecken der Schrift als Mikromechanik des Sinns im klassischen Zeitalter deutscher Literatur (Diss. München 1989). - Auch auf Seiten der Kunsthistoriker hat der Text natürlich Interesse gefunden. Einen streckenweise recht problematischen Interpretationsversuch hat Helmut Börsch-Supan unternommen: "Bemerkungen zu Caspar David Friedrichs 'Mönch am Meer,"' Zs. d. dt. Vereins für Kunstwissenschaft, 19 (1965), 63-76, hier 70ff. Auf Kleists Bild der weggeschnittenen Augenlider beschränken sich Werner Hofmanns anregende und fruchtbare Bemerkungen: Das irdische Paradies: Kunst im 19. Jahrhundert (1960), S. 78f. Mit derselben Metapher beschäftigt sich Jörg Traeger, der allerdings mehr den kunstgeschichtlichen und bildtheoretischen Kontext (David und Turner) analysiert als Kleists Text oder Friedrichs Gemälde: "'... Als ob einem die Augenlider weggeschnitten wären': Bildtheoretische Betrachtungen zu einer Metapher von Kleist," Kleist-Jb. (1980), 86-106. In seinem dem Mönch am Meer gewidmeten kleinen Exkurs geht neuerdings auch Manfred Momberger auf Kleists Metapher ein: Sonne und Punsch: Die Dissemination des romantischen Kunstbegriffs bei E.T.A. Hoffmann (1986), S. 149. - Zu nennen ist schließlich die schmale Forschung zu Brentanos und Arnims Vorlage. Neben den Bemerkungen von Susanne Harms, Clemens Brentano und die Landschaft der Romantik: Mit besonderer Berücksichtigung seiner Beziehungen zur romantischen Male- 
rei (Diss. Würzburg 1932), S. 25f., vgl. Marshall Brown, The Shape of German Romanticism (1979), S. 69-78. Eine ausführliche Analyse, die sich aber mit der hier vorgenommenen nicht deckt, hat erst jüngst Gerhard Kurz vorgelegt (Anm. 6).

10 Eine Auswahl: Werner Sumowski, Caspar David Friedrich-Studien (1970), S. 34: "... Kleist, der kongeniale Deuter des 'Mönchs am Meer."' - Börsch-Supan/Jähnig (Anm. 2), S. 303: "... da das Bild ... von Heinrich von Kleist in einem enthusiastischen Aufsatz besprochen ist..." - Sembdner (Anm. 5), S. 184: "Auch ist die Behauptung Kleists, daß einem bei der Betrachtung gleichsam die Augenlider weggeschnitten wären, nicht gerade als ein Lob aufzufassen." - Momberger (Anm. 9), S. 149: "Kleist erlebt das Bild als Gewalttat..." - Eckart Kleßmann, Die deutsche Romantik, 4. Aufl. (1987), S. 121: "Wirklich begriffen hat wahrscheinlich keiner dieser drei Autoren den 'Mönch am Meer'...."

11 So z.B. Rehder (Anm. 9), S. 175f. - Momberger (Anm. 9), S. 149. - Gebhardt (Anm. 9), S. 487, erwähnt zwar Brentanos "Anteil" an dem Text, behandelt diesen dann aber umstandslos als eine Einheit.

12 Kleßmann (Anm. 10), S. 96.

13 Das ist die verbreitetere Variante. Vgl. Hubert Schrade, "Philipp Otto Runge und Caspar David Friedrich," Die Großen Deutschen: Neue Deutsche Biographie, hrsg. Willy Andreas und Wilhelm von Scholz (1936), III, 113-139, hier 131. - Caspar David Friedrich: Katalog der Hamburger Kunsthalle, hrsg. Werner Hofmann (1974), S. 163. - Traeger, "Metapher" (Anm. 9), S. 90. - Ders., "Philipp Otto Runge und Caspar David Friedrich," Runge: Fragen und Antworten. Ein Symposion der Hamburger Kunsthalle (1979), S. 96-114, hier S. 110. - Rolf Günter Renner, "Schrift-Bilder und Bilder-Schriften: Zu einer Beziehung zwischen Literatur und Malerei," Freiburger Universitätsblätter, 85 (Okt. 1984), 35-58, hier 49.

14 Herbert von Einem, "Die Symbollandschaft der deutschen Romantik," Stil und Überlieferung: Aufsätze zur Kunstgeschichte des Abendlands (1971), S. 210-226, hier S. 221. - Hans Ost, Einsiedler und Mönche in der deutschen Malerei des 19. Jahrhunderts (1971), S. 108, 110. - Philologische Kunde aus weiter Ferne auch bei Schrade (Anm. 13), S. 130: "... in den Galeriegesprächen ..., die Brentano, Arnim und Kleist anläßlich der Ausstellung des 'Mönchs am Meer' in der Berliner Akademie erlauschten und in den 'Abendblättern' (1810) veröffentlichten." Das führt auf ein editionsgeschichtlich nicht uninteressantes Faktum: Tatsächlich nämlich kursieren nach wie vor Textwiedergaben, die derartigen Gerüchten entsprechen. Eine dem Triumvirat Kleist, Brentano und Arnim zugeschriebene, mit neuer Absatzgliederung versehene und nur als hanebüchen zu bezeichnende Klitterung aus dem Text der Abendblätter und der dort gestrichenen Fortsetzung Brentanos und Arnims findet sich in Caspar David Friedrich in Briefen und Bekenntnissen, hrsg. Sigrid Hinz, 2. Aufl. (1974), S. 213-217. Hinz hat ihren Text der von Kurt Karl Eberlein herausgegebenen Ausgabe: Caspar David Friedrich, Bekenntnisse (1924), S. 250ff., entnommen. Eberlein wiederum dürfte von den kompilatorischen Künsten Otto Fischers inspiriert worden sein. Vgl. dessen Ausgabe: Caspar David Friedrich, Die romantische Landschaft: Dokumente und Bilder (1922), S. lff. Noch von Einem, S. 221, und Ost, S. 108, gehen auf Eberlein zurück. Es muß hingegen kaum erwähnt werden, daß auch die älteren Kleist-Ausgaben den korrekten Text der Abendblätter enthalten, vgl. etwa Heinrich von Kleists Werke, im Verein mit Georg Minde-Pouet und Reinhold Steig hrsg. Erich Schmidt (o.J. [1904/05]), IV, 230f. (vgl. S. 405 zur Verfasserschaft).

15 Berliner Abendblätter (Anm. 4), S. 78.

16 Auf diese Differenz haben - mit unterschiedlich guten Gründen - bezeichnenderweise nur solche Autoren hinweisen können, die auch die philologischen Gegebenheiten besser als nur vom Hörensagen kannten. Vgl. Steig (Anm. 5), S. 267. - Sembdner (Anm. 5), S. 183f. - Börsch-Supan, "Mönch am Meer" (Anm. 9), S. 70ff. Burwick (Anm. 6), S. 42f. u.ö.

17 Ich zitiere dabei den Text grundsätzlich nach den Abendblättern (Anm. 4). Die von Brentano stammenden Sätze wurden jeweils mit dessen ursprünglichem Text verglichen; bedeutendere Abweichungen werden zitiert nach GS (Anm. 6).

18 Diese Fügung stammt von Kleist. Bei Brentano hieß es: "... daß man Alles zum Leben vermißt, und seine Stimme doch im Rauschen der Fluth... vernimmt" (GS, 424). Daß Kleist das Possessivpronomen "seine" mit Recht auf "Leben" bezieht, scheint mir aufgrund der durch die adversative Konstruktion ("doch") hergestellten Beziehung zwischen beiden unbezweifelbar. Anders Marshall Brown (Anm. 9). Seine Übersetzung des Satzes lautet: "[...] missing everything pertaining to life, and yet perceiving one's voice in the murmuring of the tide..." 
(S. 215, 70). Dieses Mißverständnis ist großenteils für Browns schiefe Interpretation der ersten Sätze Brentanos verantwortlich: "Evidently both nature and art cause a fundamental dissatisfaction, but the personal involvement and frustration are greater in confrontation with nature.... Nature responds to the call of humanity with a profound stasis" (70).

19 Vgl. GS, S. 427f. - Ich bezweifle, daß sich Brentanos Eingangssätze auf die Theorie des Erhabenen beziehen lassen, wie Gerhard Kurz (Anm. 6, S. 131) und - andeutungsweise - Rolf Günter Renner (Anm. 13, S. 49) meinen. Die bisherige Analyse hat gezeigt, daß Brentanos Spannung von "Anspruch" und "Abbruch" etwas ganz anderes ist als der für die Erhabenheitskonzeptionen charakteristische Umschlag eines drohenden (nicht also, wie bei Brentano, verlockenden) Selbstverlusts in die Erhebung des Subjekts über die Natur. Zum Erhabenen und seinem Verhältnis zur Sehnsucht vgl. u. die Abschnitte III und IV dieser Arbeit. - Ganz ähnlich wie Brentano hat übrigens später Carl Gustav Carus die Attraktion des Meeres beschrieben. In einem Kapitel, das "Von der Wirkung einzelner landschaftlicher Gegenstände auf das Gemüt" handelt, liest man folgendes: "Endlich das Wasser, als viertes Hauptelement des Naturlebens, inwiefern aus ihm alles Lebendige dieser Erde sich erschließt, in ihm die Unendlichkeit des Himmels sich widerspiegelt (recht eigentlich der Himmel auf Erden zu nennen), zieht uns mit doppelten Banden an, und wie es lebenstätig erbrandend und rauschend das Gefühl erregt und belebt, erweckt uns sein heiterer oder dunkler Spiegel das Gefühl unendlicher Sehnsucht." Neun Briefe über Landschaftsmalerei, hrsg. Kurt Gerstenberg (o.J.), S. 59.

20 Geschichte der poetischen Literatur Deutschlands, Werke, III (1976), S. 558.

21 Die ergiebigsten Ansätze zur Analyse der Sehnsuchtsthematik finden sich bei Hans Jürgen Skorna, Das Wanderermotiv im Roman der Goethezeit (Diss. 1961), S. 101 ff., 108ff. - Heinz Hillmann, Bildlichkeit der deutschen Romantik (1971), S. 64ff., 131ff., 228ff. - Lothar Pikulik, "Bedeutung und Funktion der Ferne bei Eichendorff," Aurora, 35 (1975), 21-34. - Ders., Romantik als Ungenügen an der Normalität: Am Beispiel Tiecks, Hoffmanns, Eichendorffs (1979), S.361ff., 397ff. Vgl. ferner auch Theodore Gish, "'Wanderlust' and 'Wanderleid': The Motif of the Wandering Hero in German romanticism," Studies in Romanticism, 3 (1963/64), 225-239.

22 Dieser Vorgang müßte also idealtypisch in dem von Reinhart Koselleck skizzierten Prozeß der "Verzeitlichung der Utopie" zwischen den "räumlichen Gegenwelten der überkommenen Utopien" und der "Zukunftsutopie" situiert werden. Vgl. "Die Verzeitlichung der Utopie," Utopieforschung: Interdisziplinäre Studien zur neuzeitlichen Utopie, hrsg. Wilhelm Voßkamp (1985), S. 1-14, hier S. 2 f.

23 Hillmann (Anm. 21), S. 66ff. u.ö.

24 "Über einige Schönheiten der Gebirgsgegenden," Popularphilosophische Schriften, hrsg. Kurt Wölfel (reprograph. Nachdruck 1974), II, 1089f.

25 Brief vom 21. Junius, Goethes Werke, hrsg. im Auftrage der Großherzogin Sophie von Sachsen, I. Ab:., XIX (1899), S. 39. - Fast wörtlich kehrt diese Feststellung in Karl Philipp Moritz' "psychologischem Roman" Anton Reiser wieder, für den Goethes Werther bekanntlich eine bedeutende Rolle spielt: "[...] sobald das Dort nun Hier wurde, hatte es auch alle seinen Reiz verloren, und der Quell der Freude war versiegt." Karl Philipp Moritz, Werke in zwei Bänden (1976), II, 437.

26 Ludwig Tieck, William Lovell, hrsg. Walter Münz (1986), S. 107, 124. - E.T.A. Hoffmann, Lebens-Ansichten des Katers Murr, ders., Die Elixiere des Teufels. Lebens-Ansichten des Katers Murr, Nachwort Walter MüllerSeidel (1961), S. 356. - Vgl. Hillmann (Anm. 21), S. 66.

27 Ludwig Tieck, Franz Sternbalds Wanderungen, hrsg. Alfred Anger (1966), S. 310, S. 297f. - Clemens Brentano, Godwi oder Das steinerne Bild der Mutter, Werke, hrsg. Friedhelm Kemp, 2. Aufl. (1973), II, 149. - Joseph von Eichendorff, Ahnung und Gegenwart, Werke, II (1970), S. 37f., S. 69f. - Vgl. auch Eichendorff, Eine Meerfahrt, ebd. S. 744.

28 In E.T.A. Hoffmann, Fantasie- und Nachtstücke, mit einem Nachwort von Walter Müller-Seidel (1976), S. $75 f$.

29 Stringent wird diese Problematik beschrieben bei Peter von Matt, Die Augen der Automaten: E.T.A. Hoffmanns Imaginationslehre als Prinzip seiner Dichtkunst (1971), S. 38-75. 
30 Wie Anm. 27, S. 310.

31 Wie Anm. 26, S. 358.

32 Heinz Hillmann (wie Anm. 21), S. 66.

33 Vgl. z.B. Tieck, William Lovell (Anm. 26), S. 11, S. $124 f$.

34 Ahnung und Gegenwart (Anm. 27), S. 216f. - In diesem Zusammenhang gewinnt die Kreismetapher auch bei anderen Autoren Bedeutung. Häufig veranschaulicht sie das Eingeschlossensein in einer schlechten Immanenz, die nicht transzendiert werden kann. Die Bewegung innerhalb ihrer wird zum leeren Kreiseln. So jedenfalls deutet der Kapellmeister Kreisler in Hoffmanns Kater Murr (Anm. 26) seinen Namen (S. 352). Vgl. dort auch weitere Verwendungen der Kreismetapher (S. 318, 430, 499). - Früher schon hatte Karl Philipp Moritz die Kreismetapher in einem ganz ähnlichen Sinn verwendet. Anton Reiser (Anm. 25), S. 357.

35 Hillmann (Anm. 21), S. 80. Dort auch Belege für diese Form der Bewegung. - Ein schönes Beispiel für das Zurückweichen der Ferne und des Gesuchten in ihr findet sich in E.T.A. Hoffmanns Märchen Das fremde Kind, ders., Die Serapions-Brüder, mit einem Nachwort von Walter Müller-Seidel (1976), S. 492.

36 GS, S. 428. Diese Aussage ist zugleich ein neuerlicher Beleg dafür, daß es legitim ist, die eingangs von Brentano analysierten "Empfindungen" unter den Begriff der Sehnsucht zu bringen.

37 Brentano, Godwi (Anm. 27), S. 168.

38 Sehr plastisch wird der genannte Zusammenhang in Dichter und ihre Gesellen, Eichendorff, Werke (Anm. 27), II, 422.

39 Vgl. z.B. Der goldne Topf, ders., Fantasiestücke (Anm. 28), S. 197. - Vgl. Tieck, William Lovell (Anm. 26), S. 124, 157. - Ders., Franz Sternbalds Wanderungen (Anm. 27), S. 306.

40 Eichendorff, Ahnung und Gegenwart (Anm. 27), S. 216. - Vgl. Tieck, Der getreue Eckart und der Tannenhäuser, ders., Phantasus, hrsg. Manfred Frank (1985), S. 174.

41 Brief vom 21. Junius, Goethes Werke (Anm. 25), S. 39.

42 In Novalis, Schriften, hrsg. Paul Kluckhohn und Richard Samuel, 3. Aufl., I (1977), S. 205. - Am prägnantesten wird dieser Zusammenhang in Tiecks Erzählung Der getreue Eckart und der Tannenhäuser (Anm. 40), S. 173f.: "Ich kann dir nicht ausdrücken, welche Wehmut, welche unaussprechliche Sehnsucht mich plötzlich ergriff,... wenn ich dem Zug der Wolken nachsahe, die lichte herrliche Bläue erblickte, die zwischen ihnen hervordrang... Oft ergriff mich die Lieblichkeit und Fülle der herrlichen Natur, daß ich die Arme ausstreckte und wie mit Flügeln hineinstreben wollte, um mich wie der Geist der Natur über Berg und Tal auszugießen, und mich in Gras und Büschen allseitig zu regen ...." Vgl. ebd. S. 178. - Jean Paul, Flegeljahre, Werke in zwölf Bänden, hrsg. Norbert Miller (1975), IV, 717: "Wohin ich nur blicke, so find' ich mein liebes Blau, am Flachs in der Blüte, an den Kornblumen und am göttlichen unendlichen Himmel, in den ich gleich hineinspringen möchte wie in eine Flut."

43 So Tieck, Der getreue Eckart (Anm. 40), S. 178. Ähnlich auch bei Eichendorff, etwa in der Gestalt der Gräfin Romana in Ahnung und Gegenwart (Anm. 27), deren "Und ich mag mich nicht bewahren!" (S. 119) den Wunsch nach Selbstverlust in der Entgrenzung formuliert. Von hier aus kann - was häufig, etwa von Pikulik, übersehen wird - auch das Motiv der Ferne einen bedrohlichen Zug gewinnen: Man kann sich in ihr verlieren.

44 Wie Anm. 42, S. 33. - Der Kapellmeister Kreisler, der diese Sätze enthusiastisch zitiert (Kater Murr [Anm. 26], S. 355), spricht von "jener ewigen Sehnsucht, die nichts will als sich selbst" (ebd. S. 513). - Wie sehr die Gegenstände der Sehnsucht lediglich Anlaß für diese sind und in ihr als bloß funktional erkannt und damit entwertet werden, zeigt sich in Jean Pauls Flegeljahren (Anm. 42), S. 1052.

45 Wie Anm. 27, S. 38.

46 Zum Problem vgl. besonders Dieter Arendt, Der 'poetische Nihilismus' in der Romantik: Studien zum Ver- 
Begemann: Brentano und Kleist vor Friedrichs Mönch am Meer, Seite 27

hältnis von Dichtung und Wirklichkeit in der Frühromantik (1972), v.a. I, 130-181.

47 Caspar David Friedrich: Katalog der Hamburger Kunsthalle (Anm. 13), S. 4lf. - Zur Rückenfigur bei Friedrich vgl. ferner Willi Wolfradt, Caspar David Friedrich und die Landschaft der Romantik (1924), S. 41ff. - Herbert von Einem, "Symbollandschaft" (Anm. 14), S. 223. - Ders., "Ein Vorläufer Caspar David Friedrichs?," ebd., S. 227-235. - Sumowski (Anm. 10), S. 24. - Caspar David Friedrich: Auge und Landschaft. Zeugnisse in Bild und Wort, hrsg. Gerhard Eimer (1974), S. 47f.

48 Diese Auffassung vertreten etwa Schrade (Anm. 13), S. 130f., H.M. Brown (Anm. 9), S. 162, Gebhardt (Anm. 9), S. 487, und Burwick (Anm. 6), S. 38. Wenig kann auch die Deutung Börsch-Supans für sich ins Feld führen. Der Bildbetrachter finde zwischen sich und dem Bilde die "Äußerungen des Publikums. Er variiert diese Situation noch in der Vorstellung, daß er zum Kapuziner wird und nun statt auf die See auf den Besucher blickt...." Börsch-Supan, "Mönch am Meer" (Anm. 9), S. 71.

49 Brentano hatte geschrieben: "blickte" (GS, 424).

50 Es ist daher kein Widerspruch, wenn Sehnsucht "vor dem Bilde unmöglich" genannt wird, es etwas später aber bei Brentano heißt: "das aber, wo hinaus ich mit Sehnsucht blickte...." Die zuerst genannte, "unmögliche" Sehnsucht wäre analog zu der des Betrachters der realen Seelandschaft, bei letzterer handelt es sich um die des Betrachters der gemalten nach Einlösung seiner ästhetischen Erwartungen durch das Bild.

51 Werner Hofmann, "Zu Friedrichs geschichtlicher Stellung," Caspar David Friedrich: Katalog der Hamburger Kunsthalle (Anm. 13), S. 69-78, hier S. 77, vgl. ebd. S. 71.

52 Ebd. S. 76f. Auf die Entzweiungsthematik haben auch hingewiesen: Inge Fleischer, Berthold Hinz, Inge Schipper, Roswitha Mattausch, "Friedrich in seiner Zeit: Das Problem der Entzweiung," Caspar David Friedrich und die deutsche Nachwelt, hrsg. Werner Hofmann (1974), S. 17-26, v.a. S. 19ff. Wie nicht anders zu vermuten, ist diese Auffassung in der Friedrich-Forschung keineswegs unumstritten. Den gegenteiligen Standpunkt vertritt etwa Sumowski (Anm. 10), S. 23f.

53 GS, S. 427. Wehende Luft und rauschendes Wasser nehmen hier offensichtlich Bezug auf Brentanos oben analysierte Eingangssätze.

54 An Friederike Volkmann, 22. 9. 1809, zit. n. Börsch-Supan/Jähnig (Anm. 2), S. 73.

55 Caspar David Friedrich: Katalog der Hamburger Kunsthalle (Anm. 13), Nr. 137, S. 222f. Nach BörschSupan/Jähnig (Anm. 2) "Frau vor der untergehenden Sonne," Nr. 249, S. 348.

56 Börsch-Supan/Jähnig (Anm. 2), Nr. 169, S. 304f.

57 "Über Gerhard von Kügelgen und Friedrich in Dresden: Zwei Briefe mitgetheilt von einer Kunstfreundin," zit. n. Börsch-Supan/Jähnig (Anm. 2), S. 78.

58 Vgl. z.B. auch Carl Töpfers Ausführungen von 1826 über das Gemälde Der Watzmann, zit. bei BörschSupan/Jähnig (Anm. 2), S. 107f.

59 Karl Friedrich Frommann in seinem Tagebuch am 24. 9. 1810, zit. n. Börsch-Supan/ Jähnig (Anm. 2), S. 303.

60 Abbildungen bei Börsch-Supan, Mönch am Meer (Anm. 9), S. 68f. - Auf einen früheren Zustand des Bildes bezieht sich offenbar auch der erst kürzlich aufgefundene kleine Selbstkommentar Friedrichs, mitgeteilt bei Helmut Börsch-Supan, "Berlin 1810. Bildende Kunst: Aufbruch unter dem Druck der Zeit," Kleist-Jb. (1987), S. 52-75, hier S. 74f.

61 Da dieser metaphorisch in die Kutte des Kapuziners geschlüpft ist und die Düne betreten hat, scheint es in der Tat nicht ganz abwegig, die Stellung des Naturbetrachters als die in Wahrheit gemeinte anzunehmen - zumal sich dessen Position leichter als eine "Stellung in der Welt" verstehen läßt als die des Ausstellungsbesuchers. Für diese Lesart des Rückbezugs plädiert - ohne Begründung - etwa Gerhard Kurz (Anm. 6), S. 130; ähnlich Traeger, "Runge und Friedrich" (Anm. 13), S. 104. In diesem Fall würde Kleist die Aussagen Brentanos offenkundig auf den Kopf stellen. Das Subjekt, dessen Situation "traurig" und "unbehaglich" statt "herrlich" wäre, würde 
nicht mehr, alles zum Leben vermissend, dessen Stimme in der äußeren Natur vernehmen, sondern wäre umgekehrt "der einzige Lebensfunke im weiten Reiche des Todes." Da es wenig wahrscheinlich ist, daß Kleist den Text auf so überdeutliche Weise konterkarieren wollte, verleihen diese Differenzen der anderen Lesart die größere Plausibilität; überdies wird mit ihr der Anschluß des folgenden Satzes, der ja dezidiert vom "Bild" handelt, überzeugender. Auch dann freilich ergibt sich ein Bruch mit Brentanos Argumentation - ein subtilerer, weniger augenfälliger.

62 August Langen, Anschauungsformen in der deutschen Dichtung des 18. Jahrhunderts: Rahmenschau und Rationalismus (1934; Neudruck 1965), S. 8.

63 Vgl. Langen, S. 26f.

64 Vgl. Langen, S. 40ff. - Die Bedeutung der Rahmenschau und des summativen Verfahrens der Bilderfolge gerade für die optische Erschließung des unermeßlichen Raums arbeitet Albrecht Koschorke in seiner noch ungedruckten Dissertation heraus: Die Geschichte des Horizonts: Grenze und Grenzüberschreitung in literarischen Landschaftsbildern (Diss. 1989).

65 An Wilhelmine von Zenge, 5. 9. 1800, Kleist, Werke (Anm. 7), II, 550f. - Daß Rahmenschau vorliegt, kann auch durch die Nennung eines die Aussicht abschließenden Gebirgszugs angezeigt werden oder durch die bloße Beschreibung einer Landschaft als "Gemälde," "Stück" oder "Szene." In seinem Buch Die dichterische Entwicklung Heinrichs von Kleist: Untersuchungen zu seinen Briefen und zu Chronologie und Aufbau seiner Werke (1968) hat auch Hans Joachim Kreutzer auf die "artifizielle Formung" der Landschaftsbeschreibungen in den Briefen Kleists hingewiesen sowie darauf, daß Kleist "fast jede Landschaft schildert, indem er sie mit einem Gemälde vergleicht" (S. 129; vgl. 128ff.). Das ist allerdings keine Eigenheit Kleists, sondern ein kultureller Topos. Vgl. Langen (Anm. 62), S. 40ff. Beispiele für Rahmenschau bei Kleist finden sich etwa in den Briefen vom 3. 9.1800 (Werke, II, 540, 542, 544), 11. 10. 1800 (579f., 581) und 4. 5.1801 (647). Man berücksichtige hier übrigens den penetrant pädagogischen, 'bildenden' Impetus der Briefe an Wilhelmine von Zenge, der möglicherweise auch auf die Beschreibung der Landschaften im Sinne einer Didaktisierung des Ästhetischen abgefärbt hat.

66 Werner Hofmann, Das irdische Paradies (Anm. 9), S. 79.

67 Die Art und Weise der Raumgestaltung Friedrichs hat schon früh für Aufregung gesorgt. In seiner 1809 erschienenen Polemik gegen den "Tetschener Altar" bemerkt Friedrich Wilhelm Basilius von Ramdohr: "Die Landschaftsmalerei legt dagegen eine Fläche vor mir nieder, auf der sie mir eine Menge von Gegenständen... szenenartig hintereinander herreiht, die sie mir stets in einiger Entfernung zeigt.... Wie angenehm gleitet in diesen letzten [d.h. den Landschaften Poussins] das Auge von einem Plane zum anderen ... so folgt daraus, daß die schöne Landschaft durchaus mehrere Plane darstellen muß, an der sich die Wohlgestalt der Linienperspektive zeigen kann, und daß die Darstellung eines einzelnen Körpers aus einer Landschaft, wie etwa eines Baumes, einer Felsenspitze, eines Hauses, einer stillstehenden Wasserfläche, gar nicht vor sie gehören." Zit. n. Hinz (Hrsg.), Caspar David Friedrich in Briefen und Bekenntnissen (Anm. 14), S. 139ff. In einem Brief an den Akademieprofessor Schulz vom 8. 2. 1809 hat Friedrich (der hier von sich in der 3. Pers. spricht) diese normative Zumutung charakteristischerweise zurückgewiesen: "Die unbedingte Forderung des Kammerherrn von Ramdohr, daß eine Landschaft durchaus mehrere Plane darstellen muß, erkennt Friedrich nicht an." Zit. ebd. S. 152. - Zur Raumgestaltung Friedrichs, insbesondere im Mönch am Meer, und ihrem Unterschied gegenüber der Tradition vgl. Hofmann, Das irdische Paradies (Anm. 9), S. 78f. - Helmut Börsch-Supan, Die Bildgestaltung bei Caspar David Friedrich (Diss. 1960), S. 5-20 (zum Mönch am Meer S. 5-7). - Ders., Mönch am Meer (Anm. 9), S. 64ff. - Eimer (Hrsg.), Auge und Landschaft (Anm. 47), S. 54, 59. - Traeger, "Metapher" (Anm. 9), S. 88f. - Matthias Eberle, Individuum und Landschaft: Zur Entstehung und Entwicklung der Landschaftsmalerei (1980), S. 228f. u.ö.

68 Das wird beispielsweise auch von Traeger, "Metapher" (Anm. 9), S. 88ff., übersehen, der die Rahmenschau als Bezugspunkt für Kleist zumindest andeutet.

69 Zum Erhabenen in der Natur und zum folgenden vgl. Christian Begemann, Furcht und Angst im Prozeß der Aufklärung: Zu Literatur und Bewußtseinsgeschichte des 18. Jahrhunderts (1987), S. 97-164. - Zur Konjunktur des Begriffs des Erhabenen vgl. ders., "Erhabene Natur: Zur Übertragung des Begriffs des Erhabenen auf Gegenstände der äußeren Natur in den deutschen Kunsttheorien des 18. Jahrhunderts," DVjs, 58 (1984), 74-110. Carsten Zelle, "Angenehmes Grauen": Literaturhistorische Beiträge zur Ästhetik des Schrecklichen im 18. Jahr- 
Begemann: Brentano und Kleist vor Friedrichs Mönch am Meer, Seite 29

hundert (1987), S. 80ff., 203ff. u.ö.

70 Immanuel Kant, Kritik der Urteilskraft, Werke in zehn Bänden, hrsg. Wilhelm Weischedel (1957), VIII, B 104, S. 349.

71 "Die Alpen," Die Alpen und andere Gedichte, hrsg. Adalbert Elschenbroich (1974), S. 15f., V. 325-330.

72 "Ueber das Erhabene und Naive in den schönen Wissenschaften," ders., Gesammelte Schriften: Jubiläumsausgabe, in Gemeinschaft mit F. Bamberger, H. Borodianski, S. Rawidowicz, B. Strauss, L. Strauss, begonnen von J. Elbogen, J. Guttmann, E. Mittwoch, fortgesetzt von Alexander Altmann, I (1929; Neudruck 1971), S. 453-494, hier S. 456.

73 Darauf hat schon Langen (Anm. 62) hingewiesen, der allerdings die Faszination des 18. Jahrhunderts vom erhabenen Fernblick massiv unterschätzt (vgl. S. 40).

74 "Über einige Schönheiten der Gebirgsgegenden" (Anm. 24), S. 1090.

75 Diese Metapher ist weit verbreitet. Belege dazu bei Begemann, Furcht und Angst (Anm. 69), S. $116,358$.

76 Rousseaus Bekenntnisse, hrsg. Konrad Wolter und Hans Bretschneider (o.J.), I, 238f.

77 Es wird hieraus deutlich, daß das Verhältnis der Landschaften Friedrichs zu den Theorien des Erhabenen komplizierter ist, als es häufig dargestellt wird. Das Urteil einer neueren Untersuchung jedenfalls - "Was Kant in seiner Analyse des ästhetischen Urteils auf theoretischer Ebene diskutiert, bringt Caspar David Friedrich anschaulich ins Bild: Erhabene Natur" - scheint mir mit Blick auf Kleists Reaktion revisionsbedürfig. Denn diese erweist gerade, daß es, zumindest mit Bezug auf den Bildbetrachter, durchaus unzutreffend ist, zu sagen: "Nicht 'Der Mönch am Meer' oder der 'Wanderer über dem Nebelmeer' als Individuen, wohl aber als Figurationen des ästhetischen Subjekts, ebenso der Maler selbst, der das Bild gestaltet, und der Betrachter schließlich, befinden sich in jener Sicherheit, die ästhetisches Genießen möglich macht." Barbara Ränsch-Trill, "'Erwachen erhabener Empfindungen bei der Betrachtung neuerer Landschaftsbilder': Kants Theorie des Erhabenen und die Malerei Caspar David Friedrichs," Kant-Studien, 68 (1977), 90-99, hier 91f. Die zitierte Untersuchung zeigt, wie problematisch es ist, einfach Kants theoretische Äußerungen auf Friedrichs Gemälde zu projizieren, ohne den historischen Stand der Wahrnehmung zu berücksichtigen.

78 In diesem Sinne deuten auch Traeger, "Metapher" (Anm. 9), S. 95, und Gebhardt (Anm. 9), S. 488, die Stelle.

79 Zit. n. Hinz (Hrsg.), Caspar David Friedrich in Briefen und Dokumenten (Anm. 14), S. 146. Es ist daher völlig berechtigt, daß Traeger, "Metapher" (Anm. 9), die Begriffe "ästhetische" und "pathologische Rührung" für die Deutung von Kleists Position zu nutzen sucht (S. 90). Da Traeger aber die Bruchstelle zwischen dem Text Kleists und dem Brentanos nicht zur Kenntnis nimmt, kann er die in der Aussage "so ward ich selbst der Kapuziner" kulminierenden Sätze Kleist und damit dessen metaphorischer Beschreibung von pathologischer Rührung zuschlagen. Daß sie jedoch aus einem ganz anderen Argumentationszusammenhang hervorgehen, dürfte oben deutlich geworden sein.

80 Über das Licht in der Malerei (1954), 6. Aufl. (1983), S. 216. Über den Raum in der Malerei des 17. Jahrhunderts schreibt Schöne (S. 194): "Der Begriff des unbegrenzten Raumes wird zu Unrecht immer wieder auf die Kunst des Barock angewandt. Er ist dort für das Sichtbare nicht am Platze.... Mit diesem Begriff des von Gott gebauten Raumes scheinen mir sowohl Weite wie Begrenztheit der von der Barockkunst gestalteten Räume treffend erfaßt werden zu können.... Das Bildlicht der alten Malerei 'eignet' einem 'gebauten' begrenzten Raum, das Bildlicht der Malerei des 19. Jahrhunderts einem ungebauten, daher eigentlich naturhaften, unbegrenzten Raum ...."

81 Über Geschichte und Vorgeschichte des Panoramas unterrichtet anschaulich Stephan Oettermann, Das Panorama: Die Geschichte eines Massenmediums (1980), v.a. die Einleitung, S. 7-40. Zum Panorama, seinem wahrnehmungsgeschichtlichen Kontext (insbesondere der nachaufklärerischen Tendenz zur Entrahmung der Bilder) und seinen kognitiven und sozialhistorischen Funktionen vgl. Koschorke, Geschichte des Horizonts (Anm. 64).

82 Journal des Luxus und der Moden (Juni 1800), S. 282, zit. n. Oettermann (Anm. 81), S. 14. 
Begemann: Brentano und Kleist vor Friedrichs Mönch am Meer, Seite 30

83 An Wilhelmine von Zenge, 16. 8. 1800, in Kleist, Werke (Anm. 7), II, 518f. - Zum Illusionismus der Panoramen vgl. Oettermann (Anm. 81), S. 4l. - Günter Hess, "Panorama und Denkmal: Erinnerung als Denkform zwischen Vormärz und Gründerzeit," Literatur in der sozialen Bewegung: Aufsätze und Forschungsberichte zum 19. Jahrhundert, hrsg. Alberto Martino (1977), S. 130-206, hier S. $136 f f$.

84 Vgl. Börsch-Supan/Jähnig (Anm. 2), S. 387.

85 Günther Grundmann, "Fragmente zu einem 'Riesengebirgspanorama' Caspar David Friedrichs?," Schlesien, 4 (1959), 148-152. - Dcrs., "Caspar David Friedrich: Topographische Treue und künstlerische Freiheit, dargestellt an drei Motiven des Riesengebirgspanoramas von Bad Warmbrunn aus," Jb. der Hamburger Kunstsammlungen, 19 (1974), 89-105. Kritik daran bei Börsch-Supan/Jähnig (Anm. 2), S. 200.

86 Gerhard Eimer, "Thomas Thorild und Caspar David Friedrich," Jb. der Hamburger Kunstsammlungen, 19 (1974), 37-42. - Ders. (Hrsg.), Auge und Landschaft (Anm. 47), S. 35-41 u.ö. - Zur Auseinandersetzung vgl. Sumowski (Anm. 10), S. 14f.

87 Zit. n. Eimer (Hrsg.), Auge und Landschaft (Anm. 47), S. 36.

88 "Voyages dans les Alpes" (1776), zit. n. Oettermann (Anm. 81), S. 30. Dort S. 29 die Abbildung von Saussures Panorama.

89 "Was Bentham wollte, war die radikale Säkularisation der göttlichen Allschau, die Demokratisierung des göttlichen Blicks durch Internalisierung...." Oettermann (Anm. 81), S. 35, vgl. auch S. 34ff. -- Zu Benthams Panopticon auch Michel Foucault, Überwachen und Strafen: Die Geburt des Gefängnisses, 3. Aufl. (1979), S. $256 \mathrm{ff}$.

90 "Äußerung bei Betrachtung einer Sammlung von Gemälden von größtenteils noch lebenden und unlängst verstorbenen Künstlern," Hinz (Hrsg.), Caspar David Friedrich in Briefen und Dokumenten (Anm. 14), S. 106.

91 Wolfradt (Anm. 47), S. 125f.

92 So auch Wolfradt (Anm. 47), S. 126. Zum "Großen Gehege" vgl. Caspar David Friedrich: Katalog der Hamburger Kunsthalle (Anm. 13), Nr. 208, S. 291. Vgl. dort auch Nr. 163 ("Mondaufgang am Meer"), S. 254.

$93 \mathrm{Zu}$ diesen Zusammenhängen vgl. Oettermann (Anm. 81), S. 22ff. "Während die Bilder der 'idealen Landschaft' dadurch, daß sie die 'ganze Welt' abbildeten, in das ihrer Komposition zugrunde liegende Sinngefüge eingebettet und von ihm gehalten wurden, haftete den maschinengefertigten Veduten trotz aller topographischen Bestimmtheit etwas Haltloses, Vereinzeltes an.... Die aus lauter 'Nebensächlichkeiten' und Zufälligkeiten zusammengesetzte Vedute verwies nicht mehr auf ein bestimmtes Sinngefüge, das im Idealen Landschaftsbild durch den Fernblick auf einen wichtigen Fluchtpunkt hin symbolisiert wurde, sondern verwies nur noch auf die außerhalb des Ausschnitts liegenden, nicht abgebildeten Nebensächlichkeiten. Die dargestellten Einzelheiten hatten nicht mehr einen Fluchtpunkt, auf den sie sich bezogen, sondern die unzähligen Details wurden nur noch vom Horizont zusammengehalten.... Mit einem Wort: der Ausschnitt drängte zur Vervollständigung... Das Drängen des Horizonts drohte die Vedute zu sprengen..." (ebd. S. 24). - Zu diesem Problem vgl. auch die Bemerkungen von Wolfgang Kemp, "Perspektive als Problem der Malerei des 19. Jahrhunderts," Kunst als Bedeutungsträger: Gedenkschrift für Günter Bandmann, hrsg. Werner Busch, Reiner Haussherr und Eduard Trier (1978), S. 405-416, hier S. 406, 408.

94 So etwa Sembdner (Anm. 5), S. 183f. - Gebhardt (Anm. 9), S. 183f. - Deutlicher noch als der Hinweis auf die "pathologische Rührung" legt dieser Satz die Vermutung nahe, Kleist habe Ramdohrs Polemik gekannt. Dort hatte es geheißen: "Aber das Bild des Herrn Friedrich [d.h. der "Tetschener Altar"] weicht von der gewöhnlichen Bahn ab. Es eröffnet eine neue, mir wenigstens bisher unbekannt gebliebene Ansicht der Landschaftsmalerei ...." Zit. n. Hinz (Hrsg.), Caspar David Friedrich in Briefen und Bekenntnissen (Anm. 14), S. 138.

95 In Kleists Werk finden sich meines Wissens keine weiteren Äußerungen zu Ossian und Kosegarten, die über deren Einschätzung durch Kleist Aufschluß gäben. Auch der Blick auf ihre Beurteilung durch das 'Publikum,' an das Kleist sich ja wendet, hilft nur begrenzt weiter. Erfreuen sich die - jedenfalls auf dem Kontinent - noch kaum als 'moderne' Schöpfungen rezipierten Werke "Ossians" um 1800 einer weithin ungebrochenen Hoch- 
schätzung - vgl. Ossian und die Kunst um 7800: Katalog der Hamburger Kunsthalle (1974). - Zu den Hintergründen: Herbert Schöffler, "Ossian: Hergang und Sinn eines großen Betrugs," Deutscher Geist im 18. Jahrhundert: Essays zur Geistes- und Religionsgeschichte (1956), S. 135-154 -, so scheint das literarische Gewicht von Ludwig Gotthard [Theobul] Kosegarten durchaus umstritten gewesen zu sein. Die Bedeutung Kosegartens für Runge und Friedrich ist bekannt - vgl. Sumowski (Anm. 10), S. 11ff. - Ost (Anm. 14), S. 1l2ff. - Runge in seiner Zeit: Katalog der Hamburger Kunsthalle (1978), passim -, ebenso aber auch seine skeptisch-kritische Beurteilung durch Humboldt, Tieck und andere. Vgl. Tagebuch Wilhelm von Humboldts von seiner Reise nach Norddeutschland im Jahre 1796, hrsg. Albert Leitzmann (1894), S. 40ff. - Ludwig Tieck, "Die neuesten Musenalmanache und Taschenbücher" (1796-1798), ders., Kritische Schriften, I (1848), S. 114f.- Vgl. auch Sumowski (Anm. 10), S. 11/98. Auch bei Brentano, aus dessen Vorlage Kleist die Namen Ossian und Kosegarten übernommen hatte, klingt dessen Nennung einigermaßen spöttisch: Lektüre für höhere Töchter (GS, S. 425). Schließlich verhilft auch die Untersuchung der literarischen Seelandschaften und Fernblicke Kosegartens zu keiner Klärung des Problems. Denn die Bezüge, die sich von ihnen zu Friedrichs Gemälden, insbesondere dem Mönch am Meer, ergeben, sind zwar vielfältig, aber diffus. Auf der einen Seite nämlich finden sich hymnische Szenerien einer fast panoramatischen Grenzenlosigkeit, die zwar literarisch nicht gerade auf dem allerletzten Stand sind, aber immerhin in einen thematischen Zusammenhang mit Friedrichs Malerei gebracht werden könnten. Vgl. z.B. "Der Rugard. Erstes Lied": "Auf deiner schroffen Felsenscheitel / Empfange mich alter Rugard! / Empfange mich, Hehrer; / Mich lüstet zu schauen / Mich lüstet zu fassen / Mit Einem staunenden Blicke / Die Küsten, die Inseln, das erdumarmende Meer! / Fern dringt, / Rings rollt / Das rastlos schwärmende Auge." Ludwig Gotthard Kosegarten, Dichtungen, 12 Bde. (1824-1827), VIII, 89. "Der Rugard. Zweites Lied": "Dennoch zu Trotze / Dem Trotzigen will ich / Erklimmen den Schroffen, / Will letzen das Auge, / Und letzen die Seele / In dämmernden Fernen, / In wühlenden Wogen, / In Räumen der weiten unendlichen Welt.../.../ Ich schaue fern. / Ich spähe links, / Ich forsche rechts..." (Ebd. S. 95f.). Vgl. auch "Jucunde. Vierte Ekloge: Die Nachfeyer": "Rings um die Schauenden lag, so fern nur reichet die Sehkraft, / Offen, enthüllt, endlos, das unermeßliche Weltall..." (Ebd. II, 186). Auf der anderen Seite begegnen jedoch Bilder einer völlig konventionellen und durchaus 'beschaulichen' Rahmenschau auf das erhabene Sujet, die allenfalls in eine kontrastive Beziehung zu Friedrich zu setzen wären. Vgl. die geradezu doppelte Rahmung in derselben Ekloge der "Jucunde": "Sitzen sahn sie den Vater am äußersten Rande des Ufers, / Einsam, emsig betrachtend die Pfeiler, welche vom Meer auf / Bis an den Saum des Gestades auf Feuerkieseln und Kreide / Aufgethürmt die Natur kunstreich in jonischer Ordnung; / Zwischen den Pfeilern hindurch erblickt man das Meer und den Kiesgrund. / Diese beschaut' er, bedacht, das Gesetz zu finden, nach welchem / In dem ursprünglichen Meer, in solcher Ordnung und Folge, / Sich die Lagen gesenkt durch manches verrollte Jahrtausend" (Ebd., S. 184f.). Mit der Wahl des einen oder anderen Bezugspunkts aber muß sich die Bedeutung der "Kosegartensche[n] Wirkung" fundamental ändern.

96 Hess (Anm. 83), S. 135. - Oettermann (Anm. 81), S. 13.

97 Vgl. Begemann, Furcht und Angst (Anm. 69), S. 142ff.

98 Dichtung und Wahrheit, 9. Buch, Goethes Werke (Anm. 25), 1. Abt., XXVII (1889), S. $256 f$.

99 An Charlotte von Stein, 3. 10. 1779, Goethes Werke (Anm. 25), IV. Abt., IV (1889), S. 71. Vgl. Humboldt (Anm. 95), S. 49f.: "Mir war der Anblick des Meeres einer der wenigen, die eigentliche Epoche in dem Gemüthe machen, der erste dieser Art seit den Schneegebirgen und Gletschern der Schweitz. Auch dieser kann es nur immer weniger geben. So wird die Natur nach und nach weniger abentheuerlich und groß, und die Seele weniger empfänglich für neue, große, und staunenerregende Gegenstände."

100 An Charlotte von Stein, 28. 10. 1779, Goethes Werke (Anm. 25), IV. Abt., IV, 107.

101 In ders., Werke (Anm. 42), V, 20ff.

102 Goethes Werke (Anm. 25), III. Abt., IV (1891), S. 154. Die bei aller Wortkargheit erstaunliche Stelle zeigt zugleich Goethes Fähigkeit, noch das, was seinen klassizistischen Kunstprinzipien grundsätzlich zuwiderläuft, in der Betrachtung zu akzeptieren und zu integrieren. Zur Distanzierung von Friedrich kommt es erst ab 1815. Vgl. dazu Eimer (Hrsg.), Auge und Landscbaft (Anm. 47), S. 64f.

103 Oettermann (Anm. 81), S. 19. - Vgl. Hess (Anm. 83), S. 133, 162f., 165, 172.

104 Ahnung und Gegenwart (Anm. 27), S. 70. - Es ist Eichendorff noch völlig bewußt, daß er das Wort "Panorama" in übertragener Bedeutung gebraucht. Das Wort bezeichnet nämlich ursprünglich als terminus technicus 
allein die Rundgemälde und wird erst später auf Rundblicke in der freien Natur und andere Formen der 'Übersicht' angewendet. Das Panorama als "Naturform" ist also ein Derivat des "Panorama[s] als Kunstform" - nicht umgekehrt. Das ist ein schöner Beleg für die oben wiedergegebene These, nach der das Panorama Seherfahrungen prägt und organisiert. Zur Wortgeschichte vgl. Oettermann (Anm. 81), S. 7f.

105 Ahnung und Gegenwart (Anm. 27), S. 13.

106 Wenn es stimmt, daß Kleist und Brentano den Mönch am Meer von ganz verschiedenen, ja unvereinbaren Positionen aus beurteilt haben, so fragt sich natürlich, wie Kleist Brentanos Vorlage gelesen hat, daß er glaubte, sie seinem "Geist" einverleiben zu können (s.o.). Daß diese Frage unbeantwortbar ist, disqualifiziert sie noch nicht als solche. Läßt man einmal die Möglichkeit beiseite, den Sachverhalt durch die bei der Redaktion einer Tageszeitung unvermeidliche Eile zu erklären, so ist vielleicht der Hinweis auf Elemente von Brentanos Text hilfreich, die Kleist im Sinne seiner Konzeption umdeuten und von denen aus er glauben konnte, Brentanos Text als ganzer sei seinem eigenen Konzept integrierbar. Eine Spannung von "Anspruch" und "Abbruch" etwa, durch die Brentano die unendliche Sehnsucht kennzeichnet, prägt in gewisser Weise auch die Erfahrung des Erhabenen, wenngleich in ganz anderer Hinsicht. Und den Satz "so ward ich selbst der Kapuziner" hätte Kleist als Andeutung des quasi panoramatischen Charakters des Gemäldes mißverstehen oder funktionalisieren können, der den Betrachter tendenziell zum Teil des malerischen Arrangements macht. Ich erinnere an den bereits zitierten Satz aus Kleists Beschreibung des Berliner Rom-Panoramas: "Man müßte auf dem Gemälde selbst stehen ...." 